\title{
Technology Transfer Personnel Exchange at the Boeing Company
}

Z. I. Antoniak

March 1993

Prepared for the U.S. Department of Energy under Contract DE-AC06-76RLO 1830

Pacific Northwest Laboratory Richland, WA 99352 


\section{Summary}

The objective of the exchange was to transfer Pacific Northwest Laboratory (PNL) technology and expertise in advanced ceramic fabric composites (ACFC) to the Boeing Defense \& Space Group (Boeing Aerospace). Boeing Aerospace was especially interested in applying PNL-developed ACFC technology to its current and future spacecraft and space missions. Boeing has on-going independent research and development (R\&D) programs on advanced radiators and heat pipes, therefore, PNL research in ceramic fabric heat pipes was of particular interest to Boeing. Thus, this exchange assisted in the transfer of PNL's ACFC heat pipe technology and other, related research capabilities to private industrial application. The project was proposed as an initial step in building a long-term collaborative relationship between Boeing and PNL that may result in future Cooperative Research and Development Agreements (CRADAs) and/or other types of collaborative efforts. 


\section{Contents}

Summary $\ldots \ldots \ldots \ldots \ldots \ldots \ldots \ldots \ldots \ldots \ldots \ldots \ldots \ldots \ldots \ldots \ldots$ ii

Technology Transfer Personnel Exchange at the Boeing Company $\ldots \ldots \ldots \ldots \ldots$

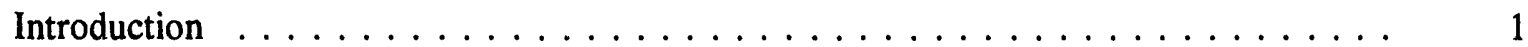

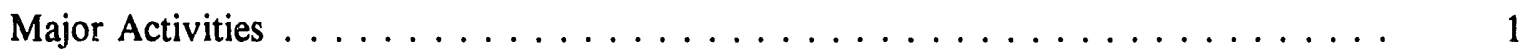

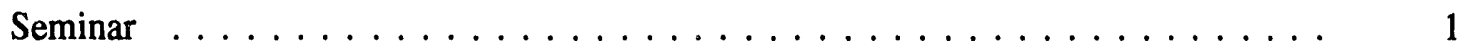

Videoconference with Boeing/Huntsville $\ldots \ldots \ldots \ldots \ldots \ldots \ldots$

Consultations and Discussions with Boeing Engineers, and Visits to

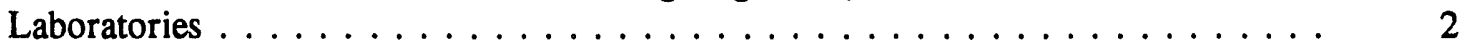

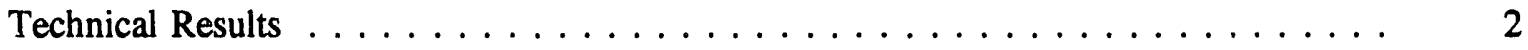

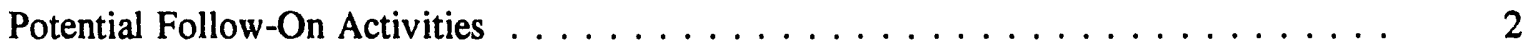

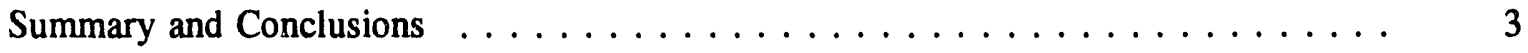

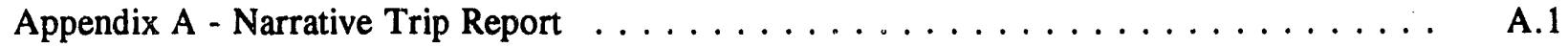

Appendix B - Presentation Viewgraphs $\ldots \ldots \ldots \ldots \ldots \ldots \ldots \ldots \ldots \ldots \ldots \ldots$ 


\section{Technology Transfer Personnel Exchange at the Boeing Company}

\section{Introduction}

The primary objective of the personnel exchange was to transfer Pacific Northwest Laboratory (PNL) technology and expertise in advanced ceramic fabric composites (ACFC) to the Boeing Defense \& Space Group (Boeing Aerospace). This summary report records the process involved from seminars to discussions with individual Boeing staff and laboratory visits. In the following sections the seminar and videoconference and constiltations and discussions are described, technical results and potential follow-on activities are explored, and conclusions are presented. Appendix A contains a narrative trip report and Appendix B contains copies of presentation viewgraphs.

\section{Major Activities}

The major activities of the personnel exchange were a seminar and videoconference held for Boeing staff. Many valuable discussions as well as visits to the various laboratories resulted from the seminar and conference.

\section{Seminar}

On September 3, 1992, a seminar was held on the subject of ACFC use in space. The presentation lasted about $11 / 3$ hours, and the question-and-answer period lasted another $3 / 4$ hour. About 20 individuals attended (16 actually signed an attendance sheet), and the topic was clearly of interest to Boeing personnel and stimulated many questions. Applications that were discussed during the seminar, besides thermal management in space, included use in cryo/fluid lines, fuel tanks, micrometeoroid shielding, space structures, as well as the potential fabrication of Nitinol ${ }^{\text {Th }}$ products using the Battelle Uniscan process. Related questions were posed regarding life tests, fatigue and corrosion, and contamination resulting from ceramic fabric particulate formation from fraying during launch and deployment.

\section{Videoconference with Boeing/Huntsville}

The videoconference took place on September 22. A seminar was presented on the subject of ACFC use in space, a somewhat modified version of the earlier seminar adapted (per suggestions by Boeing personnel) to Boeing/Huntsville needs and missions. The presentation, including questions fielded mostly during the presentation, lasted about $11 / 2$ hours. About 12 individuals attended, but no sign-up sheet or other attendance record was kept. Again, the topic was clearly of interest to Boeing personnel and stimulated many questions. Applications that were discussed during the videoconference were mainly related to the Space Station and a projected Lunar Base. Many questions were posed on ACFC shielding potential, long-term, life testing of ACFC components at PNL, and selective radiative heat transfer properties. The attendees were invited to contact appropriate PNL staff or to visit PNL, if current or future missions warranted. 


\section{Consultations and Discussions with Boeing Engineers, and Visits to Laboratories}

The seminar was followed up by contacting and meeting with individual engineers and discussing possible ACFC applications in detail. A PNL staff member was able to examine the current Boeing heat pipe research panel, and to analyze improvements in turndown ratio (i.e., range of heat rejection) that would result from ACFC application. Extensive discussions were held on the hypervelocity impact (HVI) potential of ACFCs, especially with regard to Space Station Freedom. Use of ACFCs as structural members was an option considered, with a hardenable foam fill after launch and deployment. Several individuals expressed interest in the Uniscan process for making seamless thin-wall tubing. They were introduced to the developer of this process at PNL.

\section{Technical Results}

During the personnel exchange at Boeing, a number of potential applications of ACFC technology were identified. These included applications PNL staff had already considered, plus one new one, in the advanced aircraft development area. The mass saving potential of ACFCs was recognized for HVI shielding, but near-term application is dependent on Space Station requirements. The Uniscan process elicited a great deal of interest in a possible application for making thin-walled tubing from Nitinol alloys, which would be used for spacecraft release and latch mechanisms. The need for advanced radiators was apparent; however, research in this area is influenced by the overall "health" of the space industry and its activities, as well as on Congressional funding. A role for deployable space structures to be used for future space missions that might be volume-, rather than weight-constrained, was defined. This potential role is rather limited because of the negative perception of deployable structure dependability, and that perception can only be modified with R\&D activities and positive results. Another limitation is that commercial aircraft design and materials are driven by the primary considerations of durability and performance, not mass. Therefore, any commercial airplane ACFC application would first have to demonstrate durability in a flight environment to generate extensive interest.

\section{Potential Follow-On Activities}

Within a month or two after returning to PNL, staff contacted (via telephone) those individuals at Boeing who appeared to have the greatest interest and closest near-term need for ACFC technology. Although no immediate need was identified, several strong contenders exist: application of the Uniscan process, and advanced shielding for Space Station. The Boeing variable-conductance research radiator has too low a funding level to test a concept developed by PNL staff while at Boeing; perhaps it will be possible to implement and/or test it in 1993 as an "enhanced" performance concept. Lunar and Martian base studies have received no support from Congress, but an ACFC selective radiator would be a strong contender if work on these bases resumes. Space Station shielding is being redesigned and ceramic fabric shielding is an alternative being given strong consideration. Boeing will probably test the ACFC materials early in 1993 at the University of Dayton (the materials were received from PNL). The PNL staff who developed the Uniscan process will lead follow-up efforts to adapt the process to Boeing needs and is naintaining contact with the relevant Boeing staff. 
PNL staff from the exchange will continue to maintain contact with various individuals at Boeing and, if the need and opportunity arise, will travel to either Kent or Huntsville for a collaborative effort. Because ACFC technology has only a specialized niche in advanced space missions such as Lunar and Mars bases, if these are not funded, interest in applying ACFC technology will remain low.

\section{Summary and Conclusions}

One perturbing condition during the time of the personnel exchange was the ongoing downsizing process at the Boeing Defense \& Space Group. Two years ago the Flight Thermal/ Contamination group comprised 27 staff; during the exchange it consisted of 5 staff, and one person transferred to Boeing's Commercial Airplane Group on September 25, leaving 4. The shrinking aerospace business clearly had an impact on the ability of the Boeing Defense \& Space Group's ability to accommodate the stay and fully take advantage of the technology transfer potential. During a final meeting with them, Boeing staff were apologetic that the stay at Boeing had not been more dynamic and fruitful. We ascribed this to the current downturn and ferment in the aerospace market.

Nevertheless, they had a positive overall impression regarding the personnel exchange. They felt that ACFC technology had merit (this opinion was also voiced by most of the other contacts) and could be put to good use by Boeing--if programs and funding allowed.

Under different, less-chaotic conditions, the personnel exchange at Boeing would probably have been more "hands-on" in terms of activities and experiments. Boeing Aerospace apparently was unable to assign funds for in-depth exploration of ACFC applications, whether analytical, experimental, or both. Even while there, assurances were given that somehow funding would be found to permit such exploration; this never materialized. On balance, PNL staff was given free access to individuals and the heat pipe lab, and maximum advantage was taken of this opportunity. Thus the overall evaluation of the personnel exchange at Boeing is that it was successful in transferring technology, but unsuccessful in finding immediate applications at Boeing (except for the Uniscan process). A large number of Boeing engineers have been made aware of PNL activities and progress in the space arena; it is too soon to conclude what will come of this knowledge. 
Appendix A

Narrative Trip Report 


\title{
Appendix A. Narrative Trip Report
}

\author{
Date: January 6, 1993 \\ To: $\quad$ MD Erickson \\ From: Zl Antoniak if \\ Subject: $\quad$ Iechnolegy Transfer Persennel Exchange at Boeing Aerospace

\section{INTRODUCTION}

I participated in the DOE Technology Tranfer program by spending approximately a month at Boeing Defense \& Space Group (actual dates, including travel, were 8/24 - 9/24). When I arrived at Boeing, Mr. Frank Marshall (original host), the Manager of Flight Thermal/Contamination was away on personal business but returned about a week later; however, he was immediately placed on special assignment so I had little interaction with him (he did attend my seminar). Thus my host and mentor continued to be Dr. Tim Chen, of F. Marshall's group; he and $T$. Sutey were instrumental in setting up seminars, arranging meetings, and providing me with the requisite tools (computer, desk, phone, etc.). One perturbing condition during the time of my visit was the ongoing downsizing process at the Boeing Defense \& Space Group. I was told that two years ago the Flight ThermaVContamination group comprised 27 staff; during my visit it consisted of 5 staff, and $T$. Chen transferred to Boeing's Commercial Airplane Group on 9/25, leaving 4. The shrinking aerospace business clearly had an impact on the ability of the Boeing Defense \& Space Group's ability to accommodate my stay and fully take advantage of the technology transfer potential.

\section{PURPOSE}

The objective of the exchange was to transfer PNL technology and expertise in advanced ceramic fabric composites to Boeing Defense \& Space Group ("Boeing Aerospace"). Boeing Aerospace was especially interested in applying PNL-developed ACFC technology to its current and future spacecraft and space missions. Boeing has on-going independent $R$ \& $D$ programs on advanced radiators and heat pipes, therefore PNL research in ceramic fabric heat pipes was of particular interest to Boeing. This exchange therefore assisted in the transfer of PNL's ACFC heat pipe technology and other, related research capabilities to private industrial application. The project was proposed as an initial step in building a long-term collaborative relationship between Boeing and PNL that may result in future Cooperative Research and Development Agreements (CRADAs) and/or other types of collaborative efforts. 


\section{ACTIVITIES}

\section{Seminar}

The first week or so of my stay was devoted to preliminary discussions with Boeing staff potentially interested in application of advanced ceramic fabric composite (ACFC) technology, and in planning a seminar. Both T. Sutey and T. Chen were extensively involved in the latter; $T$. Sutey provided the names of chief engineers and managers of various Boeing divisions and programs, and the final invitation list included about 70 individuals (see attached Table 1). T. Sutey was especially helpful in editing and focusing my presentation viewgraphs (which went through several major revisions; final version is attached as Appendix $B$ ) to the interests of the Boeing audience. In response to the comments, I obtained additional information from PNL (including photographs and samples of foil liners and a fabric/foil heat pipe we had constructed) to enhance the upcoming seminar.

On September 3 I held a seminar on the subject of ACFC use in space. My presentation lasted about 1 1/3 hours, and the question-and-answer period lasted another 3/4 hour or so. About 20 individuals attended (sixteen actually signed an attendance sheet; see Table 1), and the topic was clearly of interest to Boeing personnel and stimulated many questions. I followed up on this seminar by contacting and meeting with individual engineers and discussing possible ACFC applications in detail.

Applications that were discussed during the seminar, besides thermal management in space, included use in cryo/fluid lines, fuel tanks, micrometeoroid shielding, space structures, as well as the potential fabrication of NitinolTM products using the Battelle Uniscan process. Related questions were posed regarding life tests, fatigue and corrosion, and contamination resulting froin ceramic fabric particulate formation from fraying duting launch and deployment.

\section{Consultations and Discussions with Boeing Engineers}

\section{B. Hartung}

R. Hartung stopped by the day after attending my seminar, and proposed several ACFC applications, some of which we had also considered in the past but had not taken beyond the idea stage. He proposed filling a ceramic fabric/foil lined pipe with a hardenable foam material after launch and deployment in space in order to create structural members. I provided him with a sample (actually, a non-operable heat pipe about $1 \mathrm{~m}$ long) to test this concept. $\mathrm{He}$ passed this on to J. Laakso for actual experimentation.

\section{J.Laakso}

J. Laakso in the manager of Boeing's Aerospace Structures R \& D activities. Most structures they evolve and test are graphite-epoxy, and his feeling is that, with the current conservative spacecraft design philosophy, there is no real demand for deployable (or, as he termed it, "deplorable") space structures. However, his organization did respond recently to the Lawrence Livermore Lab RFP for deployable structures, and has the technical skills to work with deployable concepts if desired. He lacked any funds to test the sample I provided, and returned it to me. He then introduced me to one of his staff, E. Brogren. 
Table A.1. Seminar Invitees and Attendance List

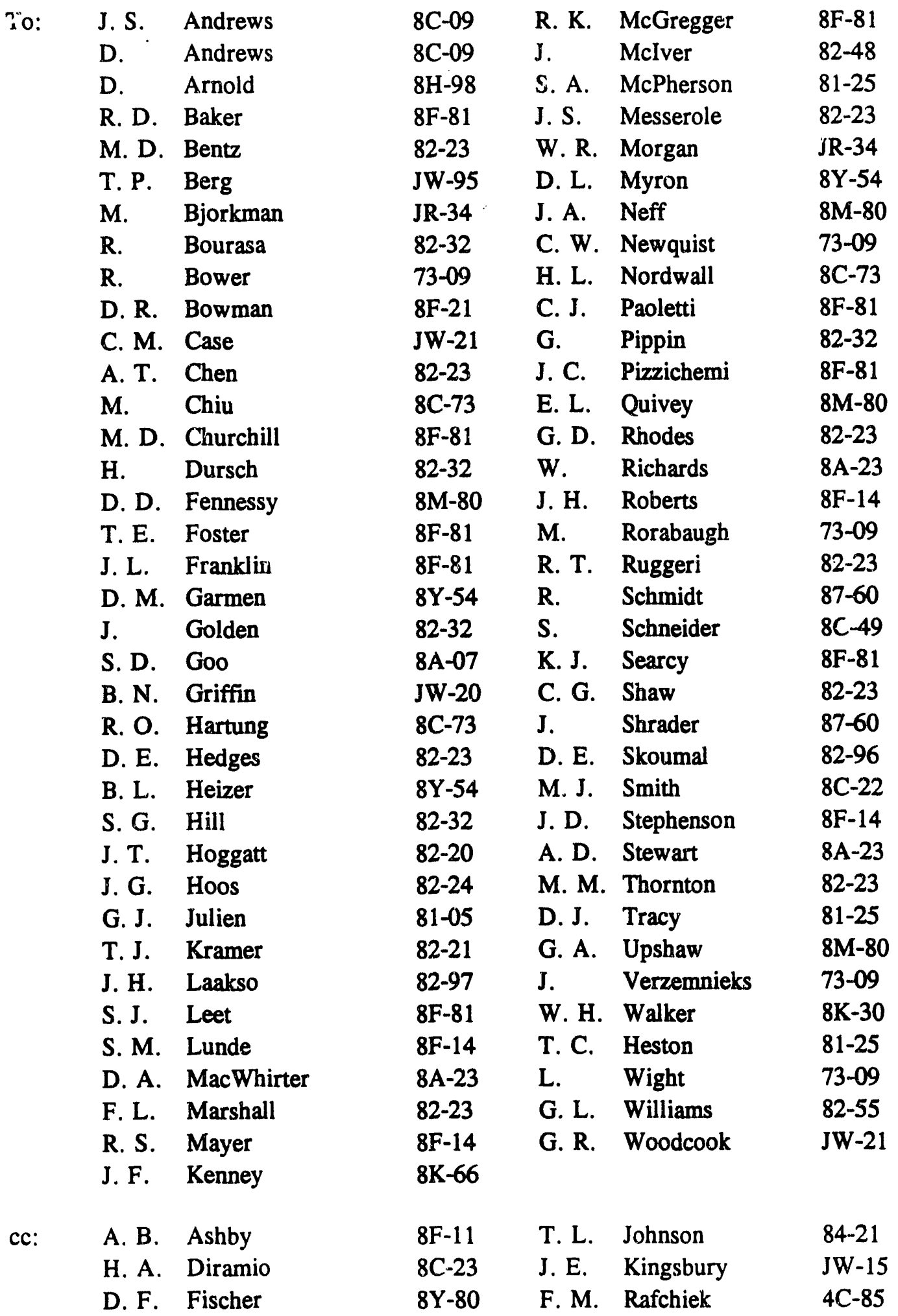




\section{Boeing Defense \& Space Group/Seminar Attendees Kent, WA}

\begin{tabular}{lrrll}
\multicolumn{1}{c}{ Name } & Mail Stop & Phone & \multicolumn{1}{c}{ Organization } \\
\cline { 5 - 5 } Tim Chen & $82-23$ & $773-1895$ & Flight/Thermal \\
Paul Weber & $8 \mathrm{~F}-14$ & $3-3081$ & EDP TC-S Design \\
Gary Dutt & $8 \mathrm{~F}-14$ & $3-3084$ & EDP TCS Design \\
Kevin Housen & $87-60$ & $3-5438$ & Physics \\
Steve Hahn & $82-97$ & $3-9565$ & Structures \\
Gregg Rhodes & $82-23$ & $3-5164$ & Flight/Thermal \\
Robert Schmidt & $87-60$ & $3-0660$ & Physics \\
Al Stewart & $8 \mathrm{~A}-23$ & $3-0625$ & Small Spacecraft \\
Tony Sutey & $8 \mathrm{C}-61$ & $3-0061$ & Space Technology Reg. \\
Mike Bentz & $82-23$ & $3-0565$ & Flight/Propulsion \\
Steve Goo & $8 \mathrm{~A}-07$ & $3-2902$ & Space Transportation \\
Dick Hertung & $8 \mathrm{C}-73$ & $3-0169$ & IUS Thermal \\
Mike Rorabaugh & $73-09$ & $234-2658$ & Materials \& Process \\
Chris Shaw & $82-23$ & $3-2014$ & Flight/Contam \\
Frank Marshall & $82-21$ & $3-9997$ & Flight \\
Jeff Parrot & $8 \mathrm{C}-76$ & $3-9223$ & IUS
\end{tabular}




\section{E. Brogren}

E. Brogren is the principal engineer involved with structures thermal analysis. I explained our ACFC heat pipe technology to him. He could see no immediate application of this technology in his area, and suggested I contact $J$. Franklin who might have some near-term interests.

\section{Franklin}

J. Franklin is a manager on the Defense (classifiad) side of the aerospace business, and has extensive experience with heat pipes and good knowledge of Stirling devices. At one time (to 1978) he worked in Richland for Sigma Research, and has been with Boeing since. He was obviously unable to communicate to me the nature of his applications, but felt that a "natural" application for ACFC technology might be to replace current space sunside radiator elements (termed OSRs). These are extremely tedious to fabricate, clean, and maintain (they consist of a mosaic-like adhesive-bonded structure of $1^{\prime \prime} \times 1^{\text {" }}$ silvered quartz tiles, sometimes numbering in the thousands) and Inconel substrate. He also gave me the names of several individuals outside Boeing that might have applications for ACFCs.

\section{J.Meserole}

I met Dr. Meserole at a conference in 1985, and we have occasional discussions over the telephone, or see each other at more recent conferences. At one time, he was very interested in our computationalcode expertise as it might be applied to analyzing rocket fuel storage and transfer in a 0-gravity environment. Several years ago, J. Cuta of PNL did a preliminary analysis using CCBRA-SFS, but it never led to a contract with Boeing to develop a better code for microgravity condition modelling.

Currently, Dr. Meserole is very active in developing NitinolTM (a Boeing-patented nickeltitanium "memory" shape alloy) space hardware, in the form of latches (e. g., to replace explosive bolts in separating rocket stages) and fluid seals. For these purposes, a great need exists for thin-walled tubing, in sizes to 12 inches diameter $\times 20$ mils wall thickness. Such tubing is now fabricated by boring/machining expensive blanks, at a cost of about $\$ 2,000$ per tube. Dr. Meserole had numerous questions regarding the PNL Uniscan process after attending my seminar, and how it might be applied to Nitinol.

Dr. Meserole was planning to give his customer (not specified) an update soon on progress with Nitinol for the above applications, and expects to offer Uniscan fabrication as an option. If all goes well, he will contact PNL and discuss an R \& D program with PNL to adapt the Uniscan process to his needs. Dr. Meserole knows S. Robinson (see below) and will also be apprised by him regarding information transferred between Boeing and PNL under the non-disclosure agreement. Finally, I invited Dr. Meserole (es I did with most individuals contacted at Boeing) to visit PNL, and discuss his applications in greater detail.

\section{B. Schmidt}

Dr. Schmidt has many years' experience in modelling and testing shielding and armor for effectiveness against hypervelocity impacts (HVI). He has developed an approach for using cadmium to simulate impacts at velocities higher than feasible with current HVI launchers and 
test equipment, and gave me several recent papers on his work. Dr. Schmidt attended my seminar, and we met on a number of occasions thereafter to discuss the use of ceramic fabric materials, especially NextelTM, for HVI shielding of spacecraft. His current work is mostly funded out of internal Boeing R \& D (IRAD) and not by Space Station (Space Station hardware development is taking place at Boeing/Huntsville, AL). However, he serves as a consultant on HVI shielding to the Huntsville component, and had an extended trip to Huntsville for that purpose during my stay.

Afier Dr. Schmidt's return from Huntsville, we met again to discuss Space Station shielding needs. It appears that the Space Station hardware is launch-mass-limited, and the expressed desire by NASA headquarters to provide enhanced shielding for Space Station (to protect against about a 1 gram micrometeoroid, vs. a much smaller "design" particle that Boeing is working toward) is unrealizable with the current design. He believes that, in the future, Space Station may require retrofitting with enhanced shielding. I proposed the use of Nextel (PNL patent pending, with NASAJohnson), which would appear to be ideal for a retrofit. It could be easily stowed for launch, and then readily "draped" to conform to equipment to be shielded. We then discussed at length the significance of the NASAJohnson HVI test data base on Nextel, extrapolation to high velocities, modelling with large hydrocodes, and the concern that astronauts could damage shielding during extravehicular activities.

I provided Dr. Schmidt with Nextel property data, and promised to send him varic us ceramic fabric samples for his HVI tests. The actual tests are performed for him by the University of Dayton; pending funding, he hopes to resume HVI tests about 1/93 and expressed willingness to test any samples I provided (note: since my return to PNL, I have sent Dr. Schmidt 3 fabric samples: Nextel 312, 440, and SiC).

\section{L.Stephenson}

J. Stephenson was unable to attend the seminar noted above, but had attended an earlier seminar I gave on 6/25/92, during a one-day visit to Boeing to discuss my upcoming stay at Boeing. J. Stephenson has an ongoing IRAD program to develop an ammonia variable-conductance heat pipe bus. This consists of grooved aluminum tubes attached to a fin radiator, with heated containers of inert gas pressurizing the tubes as required to satisfy heat transfer needs. The current design operates to a maximum of about 170 psi, with proof testing done at 500 psi, so the walls of the aluminum heat pipe tubing are relatively thick. I discussed the use of a ceramic fabric/foil tube section in the adiabatic region of this heat pipe, to reduce the conductive heat path, and increase the heat rate turn down ratio provided by this design. J. Stephenson approved this concept, but had no funds available to test it immediately. I was able to freely visit the heat pipe lab, talk with the technician (G. Frankfurt, who worked for many years first at the Douglas Labs, and then at Sigma Research, in Richland), observe setup and testing, and obtain design drawings. Using the latter, I performed somie calculations indicative of the potential reduction in heat leak rate ensuing from a proposed design with fabric/foil adiabatic sections. I also provided data and insight on PNL experience with ceramic fabric sizing removal, heat treatment and effect on flexibility, costs, metal coatings, and similar topics.

Another topic of interest to J. Stephenson is reduction of solar input to low-temperature space radiator surfaces. I gave him data on spectral radiative properties of cerarric fabrics such as Nextel and Astroquart TM, and discussed in detail the solar shield design I developed for the Solar Probe spacecrait being proposed by the jêt Prónulision Laboratory (JPL). Ho has recsntly been 
involved in the preliminary design with JPL of a Mercury spacecraft that experiences an average of 7 suns, wherein the use of Nextel for solar shielding was suggested ( 1 am not clear of this is based on any of our work/presentations/publications). He appeared to be quite interested in the design I had proposed, using multiple, umurella-like shields that utilize reflection and transmission in a series configuration to reduce the solar flux at sensitive spacecraft components to tolerable design levels. This approach differs markedly from traditional shielding techniques that rely on absorption and re-radiation of the incident solar flux from a monolithic, massive, high-temperature material such as tungsten or carboncarbon.

\section{S. Aobinson}

S. Robinson is the lead engineer on mechanism research at Boeing Defense \& Space. His manager, J. Julien, was invited to my seminar but was unable to attend, and continued to be away on travel. I therefore contacted S. Robinson regarding his interest in thin-wall Nitinol component manufacture. We had a long meeting, during which I showed him one of our fabric/foil heat pipes, plus foil tubing samples made using the Uniscan process. He also is working on Nitinol spacecraft latches (see J. Meserole, above), and other applications that are company-sensitive and he was therefore unable to describe. Recently he placed an order for thin-wall Nitinol tubing to be drawn by a local company, with delivery promised by $3 / 92$; this company was unable to produce any tubing even by the time of my stay. Nitinol itself, a Boeing invention, is currently manufactured by several companies; it is very ductile but notchsensitive, and does not work-harden. The only succesful Nitinol tubing tubing manufacture method in the past utilized rolled, seam-welded sheet, not an optimal fabrication process. I advised him that his needs for seamless Nitinol tubing could probably be readily met with the Uniscan process. He promised to discuss the information I had given him with his management and, if the interest was there, to sign a non-disclosure agreement with PNL and pursue this topic further. The response was positive, and a non-disclosure agreement between PNL and Boeing was signed 9/22/92.

Because the Uniscan process was developed at PNL by Gene Eschbach, I have relinquished this technology transfer topic, having arranged for S. Robinson and Gene to contact each other. The discussions and plans between them are ongoing, with excellent potential for some follow-on activities. I will remain involved in this particular activity only peripherally, if and where I can be of further assistance.

\section{Videoconference with Boeing/Huntsville}

T. Chen, at T. Sutey's urging, was instrumental in arranging for a videoconference with Boeing/Huntsville. My understanding of this Boeing component is that it consists of about 4,000 people whose main mission is to support Space Station and Lunar Base work performed by NASA/Marshall. It appears that Boeing/Huntsville is less affected by the current downturn in space and defense business than the Kent facility, although a small layoff there (of about 100 people) was announced during my stay at Kent.

On September 22 this videoconference took place. I presented a seminar on the subject of ACFC use in space, a somewhat modified version of my earlier seminar adapted (per suggestions by $T$. Chen and $T$. Sutey) to Boeing/Huntsville needs and missions . My presentation, including questions fielded mostly during the presentation, lasted about $11 / 2$ hours. About 12 
individuals attended, but I have no sign-up sheet or other attendance record. Again, the topic was clearly of interest to Boeing personnel and stimulated many questions.

Applications that were discussed during the videoconference were mainly related to Space Station and a projected Lunar Base. Many questions were posed on ACFC shielding potential, longterm/life testing of ACFC components at PNL, and selective radiative heat transfer properties. A copy of my viewgraphs had been sent to C. Case (who organized the Huntsville end of this conference), and at the conclusion of the videoconference he offered to provide copies to any interested attendees. I invited attendees to contact me or to visit PNL, if current or future missions warranted.

\section{Other}

T. Chen tried very hard to arrange for a meeting/seminar with Boeing's Commercial Airplane Group. He was unable to find and contact the relevant individuals in that organization during my stay.

\section{POTENTIAL FOLLOW-ON ACTIVITIES}

Within a month or so of my return to PNL, I contacted (via telephone) those individuals at Boeing that appeared to have the greatest interest and closest near-term need for ACFC technology. Although no immediate need was identified, several strong contenders exist: application of the Uniscan process, and advanced shielding for Space Station. The table below summarizes these contacts, and provides an up-to-date status review of ongoing activities at Boeing that are perceived to have a present and future high application potential.

Contact Iopic

J. Stephenson

C. Case

T. Chen

R. Schmidt
Variable-conductance radiator

Space Station/Lunar \& Mars Bases

Commercial Airplane

HVI

\section{Bemarks}

IRAD funds too low to tesi my concept now; perhaps will be able to implement/test next year as "enhanced" performance concept

Lunar and Martian applications are his responsibility at Huntsville; zeroed by Congress, he entirely funded by IRAD now; has heard nothing from Space Station people attending the videoconference; will try to interest NASA HQ in Lunar applications, esp. as $A C F C$ selective radiator

Will contact me if he sees any potential application of ACFC technology to the airplane market; we are to stay in touch

$\mathrm{He}$ is involved in Space Station shielding redesign; ceramic fabric shielding is an alternative being given strong consideration; will probably test the ACFC materials (received from PNL) in 1993 
(cont'd)

Contact

J. Meserole
Iopic

Uniscan Process
Remarks

Gene Eschbach will lead follow-up efforts to adapt the Uniscan process to Boeing needs; recent discussions with Gene indicate that he is proceeding on this

\section{POTENTIALAPPLICATIONSAND COLLABORATIONS}

During my stay at Boeing, a number of potential applications of ACFC technology were identified. These included applications we had already considered, plus one new one, in the advanced aircraft development area. The summary table below provides an overview of the main applications considered and discussed while at Boeing.

$\begin{array}{lll}\text { Potential ACFC Application } & \begin{array}{l}\text { Evaluation } \\ \text { HVI shielding }\end{array} & \begin{array}{l}\text { R. Schmidt } \\ \text { Interest Loderate }\end{array} \\ \text { Uniscan process } & \begin{array}{l}\text { J. Meserole/ High } \\ \text { S. Robinson }\end{array} \\ \text { Advanced radiators } & \text { J.Stephenson Moderate } \\ \text { " } & \text { C.Case Low }\end{array}$

Deployable Space Structures R. Hartung Low

$\begin{array}{ll}\text { Aircraft } & \text { T.Chen L Low }\end{array}$

\section{Comment}

Dependent on Space Station requirements

Great deal of interest in applying the process to make thin-walled tubing from NitinolTM alloys

Dependent on overall "health" of space industry/activities Dependent on Congressional funding

Negative perception of dependability of deployable structures must be overcome with $R$ \& $D$ activities

Primary considerations are durability and performance, not mass

\section{PLANS}

I will continue to maintain contact with the individuals noted and, if the need and opportunity arise, will travel to either Kent or Huntsville for a collaborative effort. Because ACFC technology has only a specialized niche in advanced space missions such as Lunar/Mars bases, if these are not funded, interest in applying ACFC technology will remain low. 


\section{SUMMABYAND CONCLUUSIONS}

Curing my final meeting with them, both T. Sutey and T. Chen were apologetic that my stay at Boeing had not been more dynamic and fruitful. They (and I) ascribed this to the current downturn and ferment in the aerospace market. Nevertheless, they had a positive overall impression regarding my stay. They felt that ACFC technology had merit (this opinion was also voiced by most of my other contacts) and could be put to good use by Boeing - if programs and funding allowed.

\section{OVERALLEVALUATION OFPEBSONNEL EXCHANGE}

Under different, less-chaotic conditions, I feel my stay at Boeing would probably have been more "hands-on" in terms of activities and experiments. Boeing Aerospace apparently was unable to assign funds for in-depth exploration of ACFC applications, wheiher analytical, experimental, or both. Even while I was there, assurances were given me that somehow funding would be found to permit such exploration; this never inaterialized. On balance, I was given free access to individuals and the heat pipe lab, and I took maximum advantage of this opportunity. Looking back, I still have mixed feelings regarding a more orchestrated arrangement, with stated goals agreed-upon by both organizations, and some proof by the host organization of having set funds aside to carry through on its intentions. Given the avowed intent of such a personnel exchange, it would seem that any attempts to bureaucratize the process would defeat the original purpose. The present, loosely-defined arrangement would seem to fit a R \& D activity best. Thus my overall evaluation of my stay at Boeing is that it was successful in transferring technology, but unsuccessful in finding immediate applications at Boeing (except for the Uniscan process). A large number of Boeing engineers have been made aware of PNL activities and progress in the space arena; it is too soon to conclude what will come of this knowledge.
cc:
B. Harrer
E. Pearson 
Appendix B

Presentation Viewgraphs 


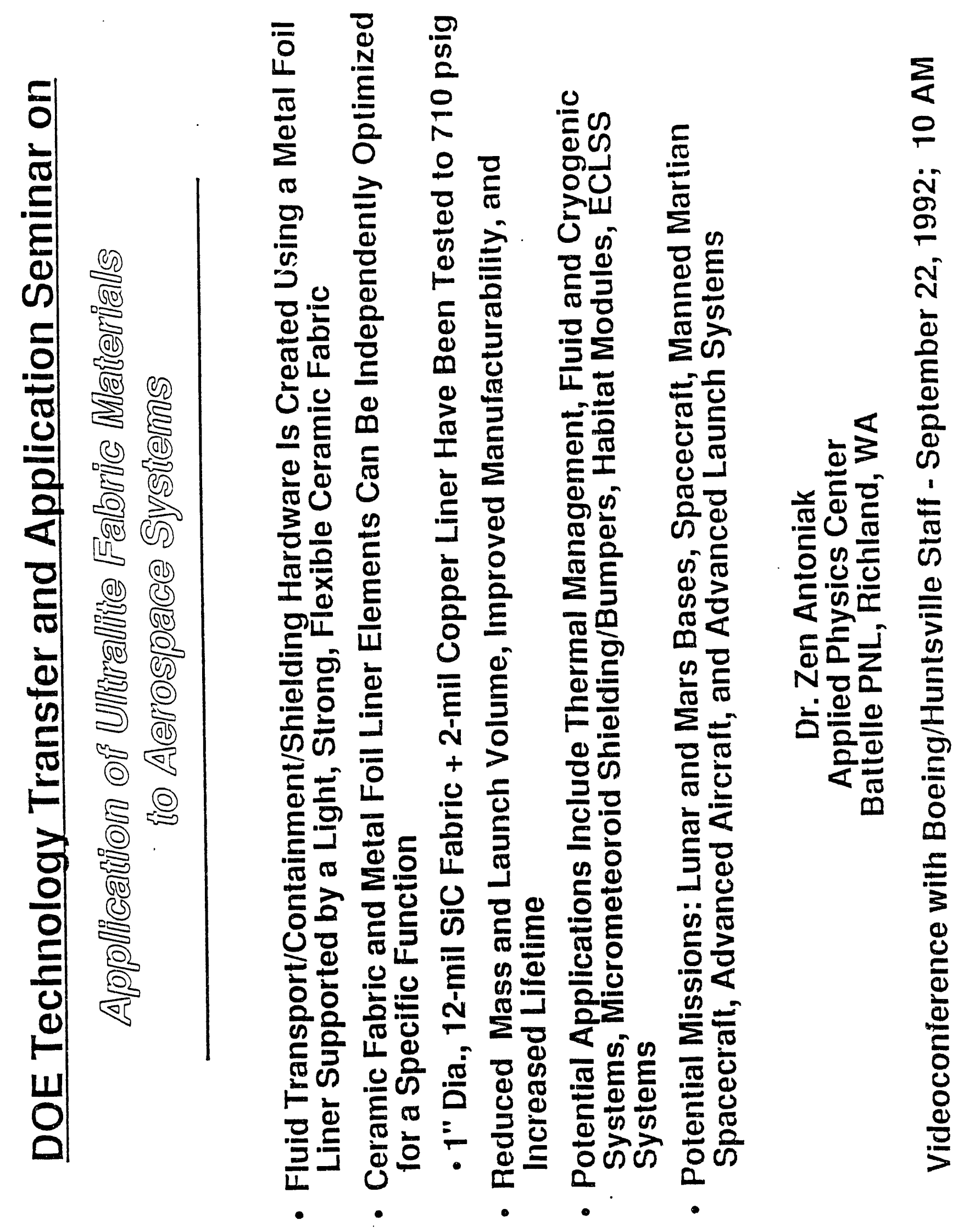

B. 1 


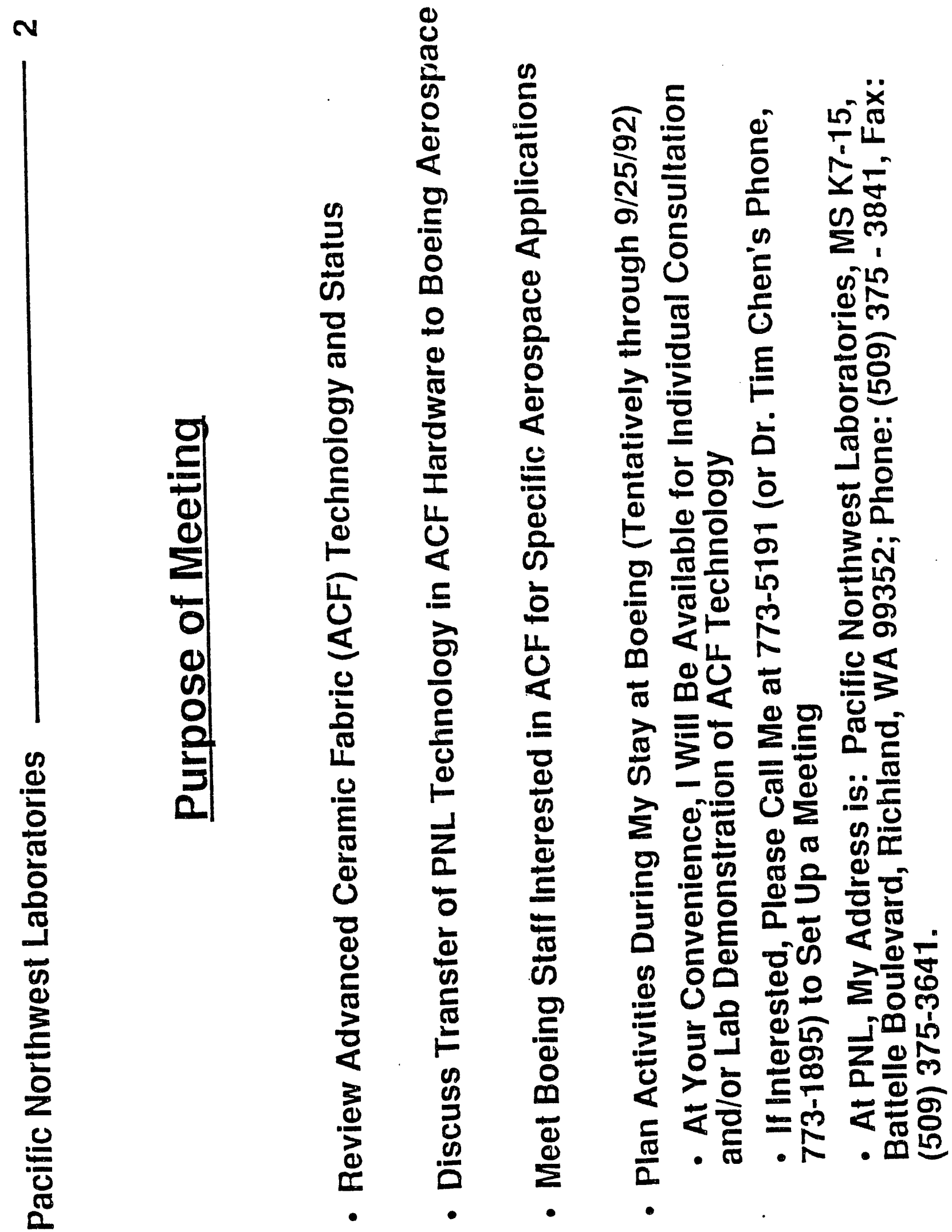

B. 2 


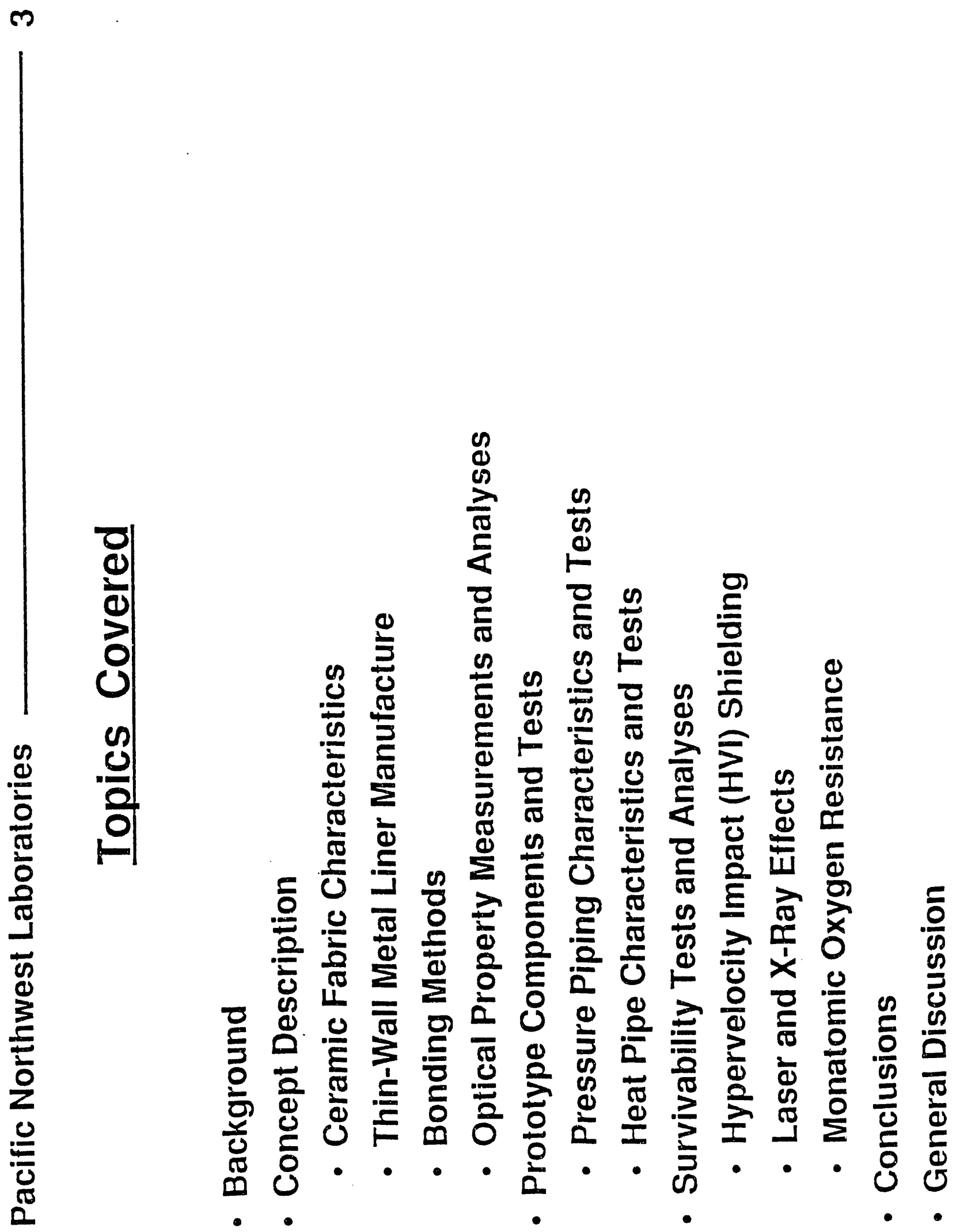

B. 3 


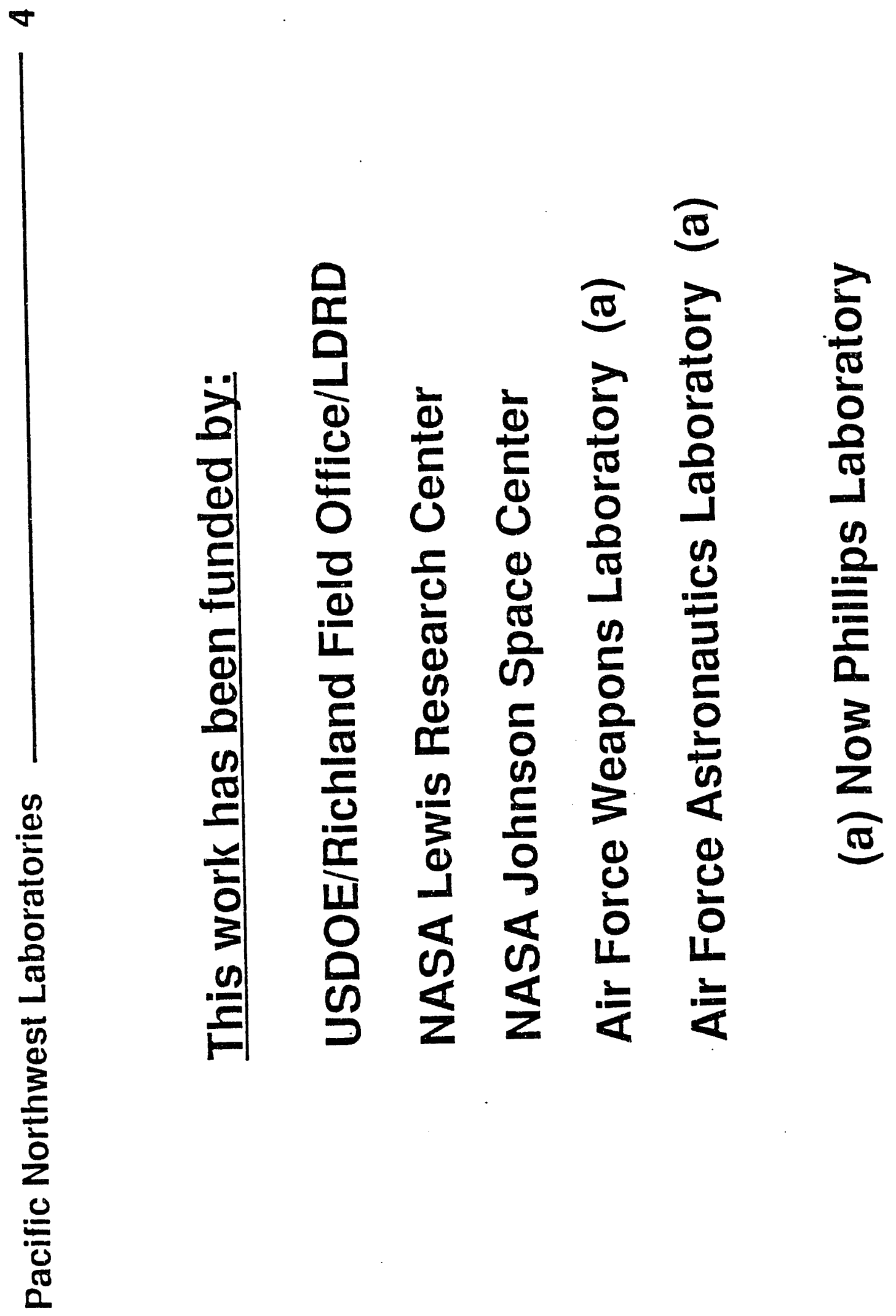

R. 4 


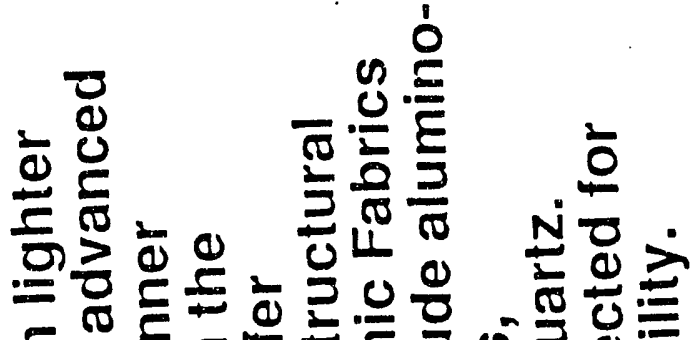

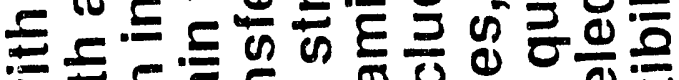

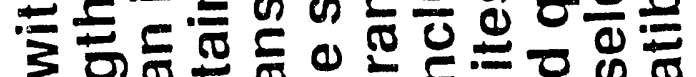

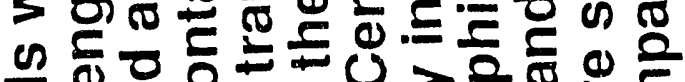
즌 은 I

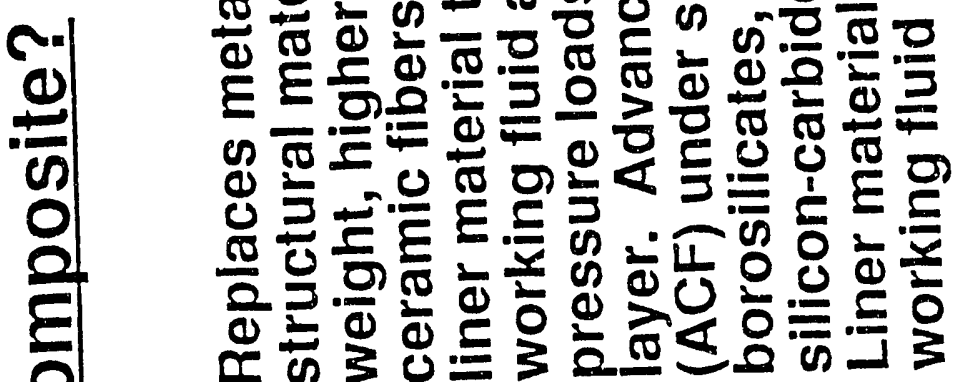
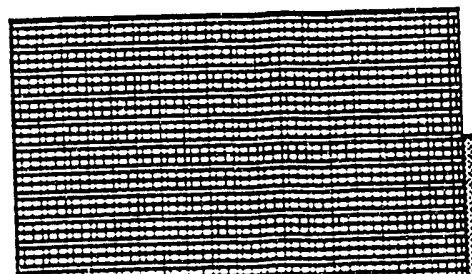

$\omega$
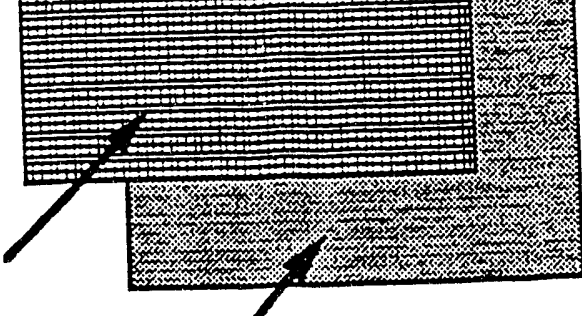


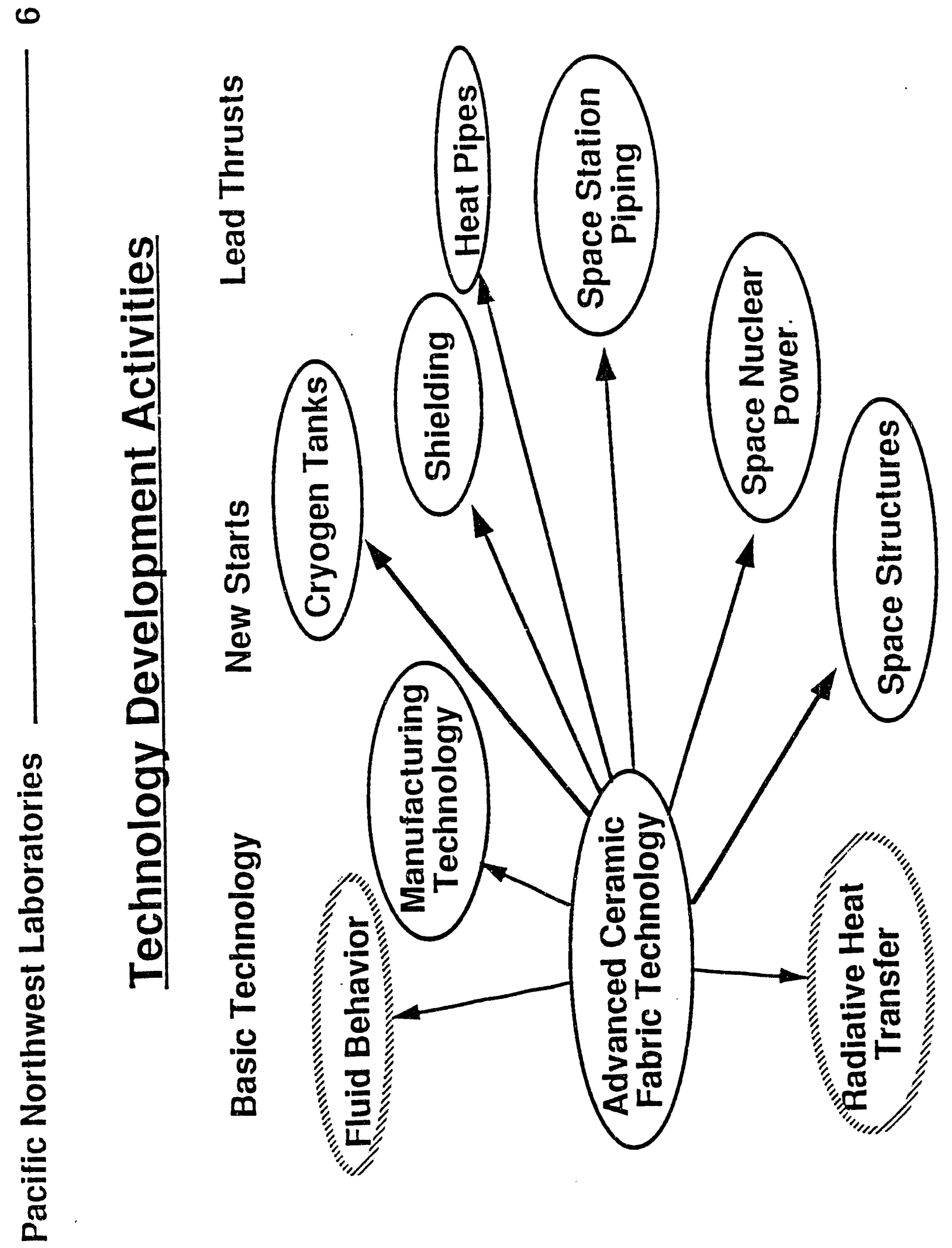




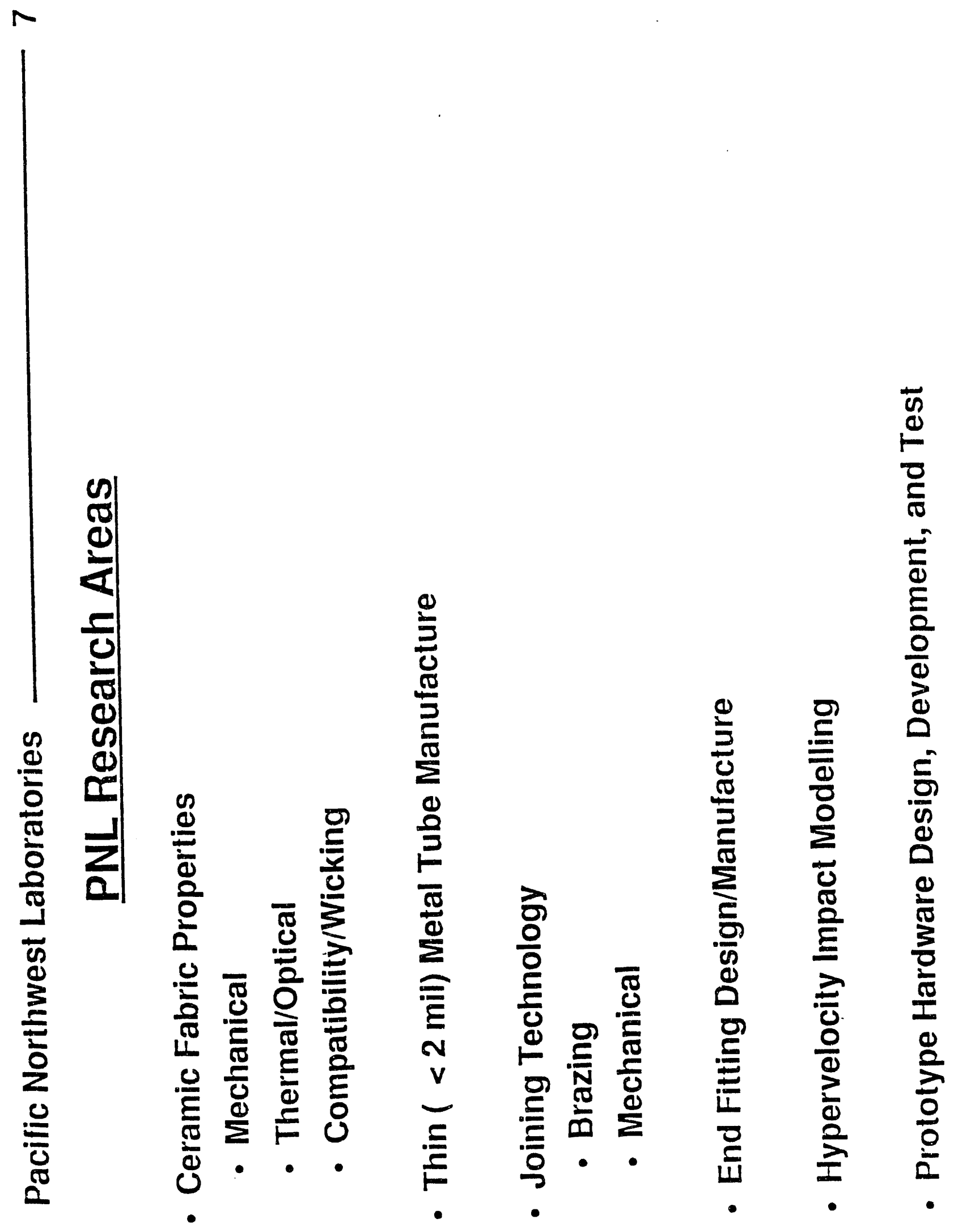

B. 7 


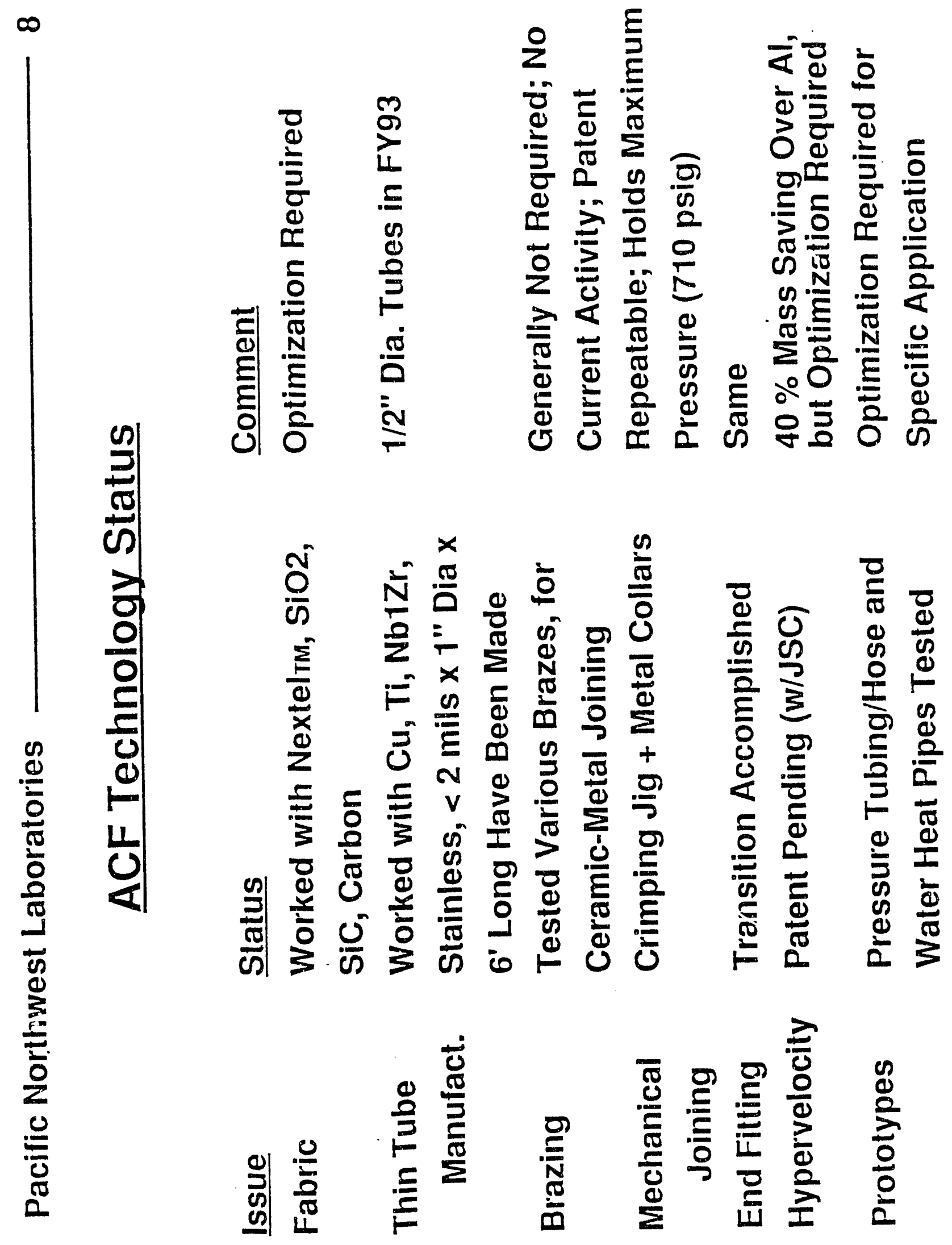




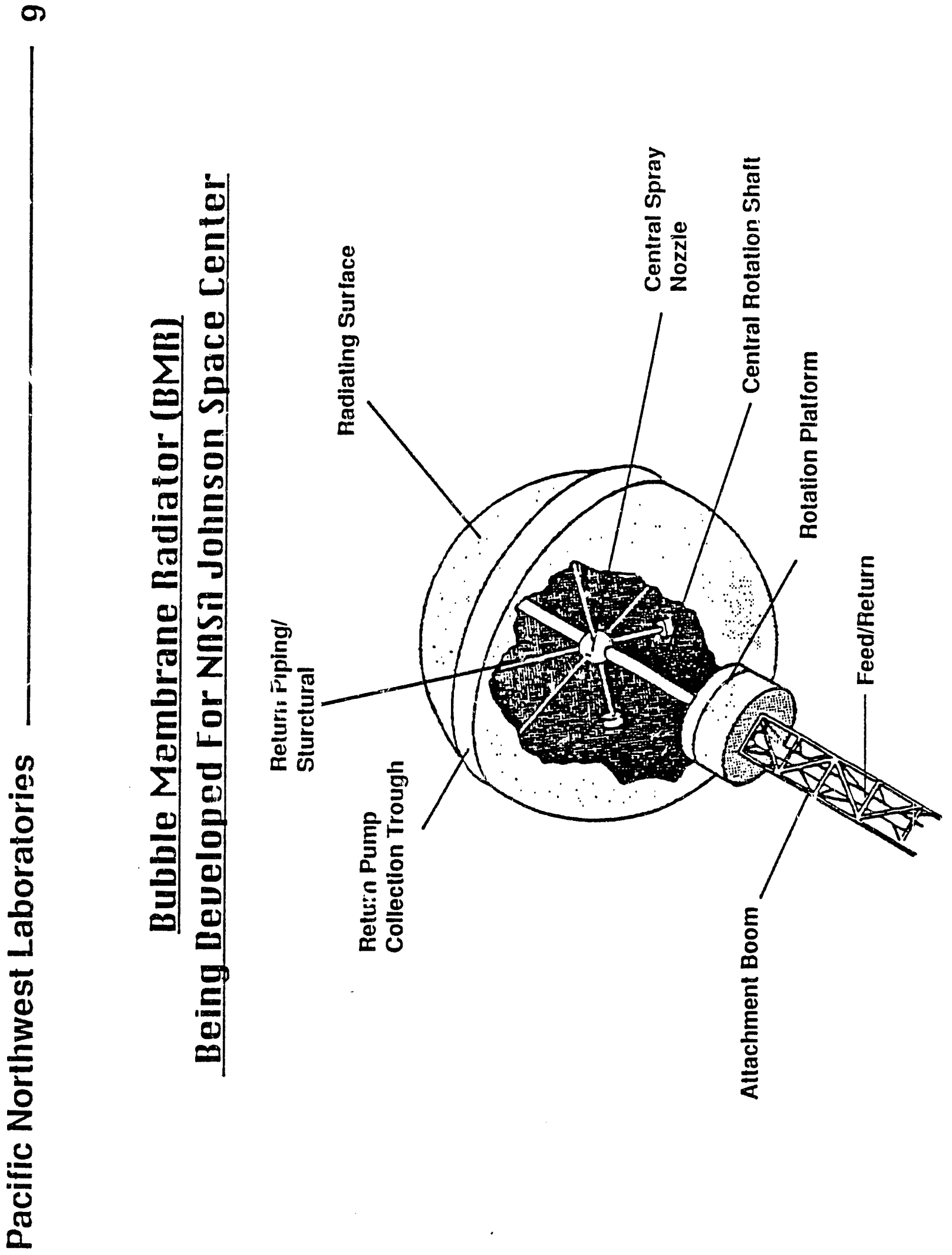




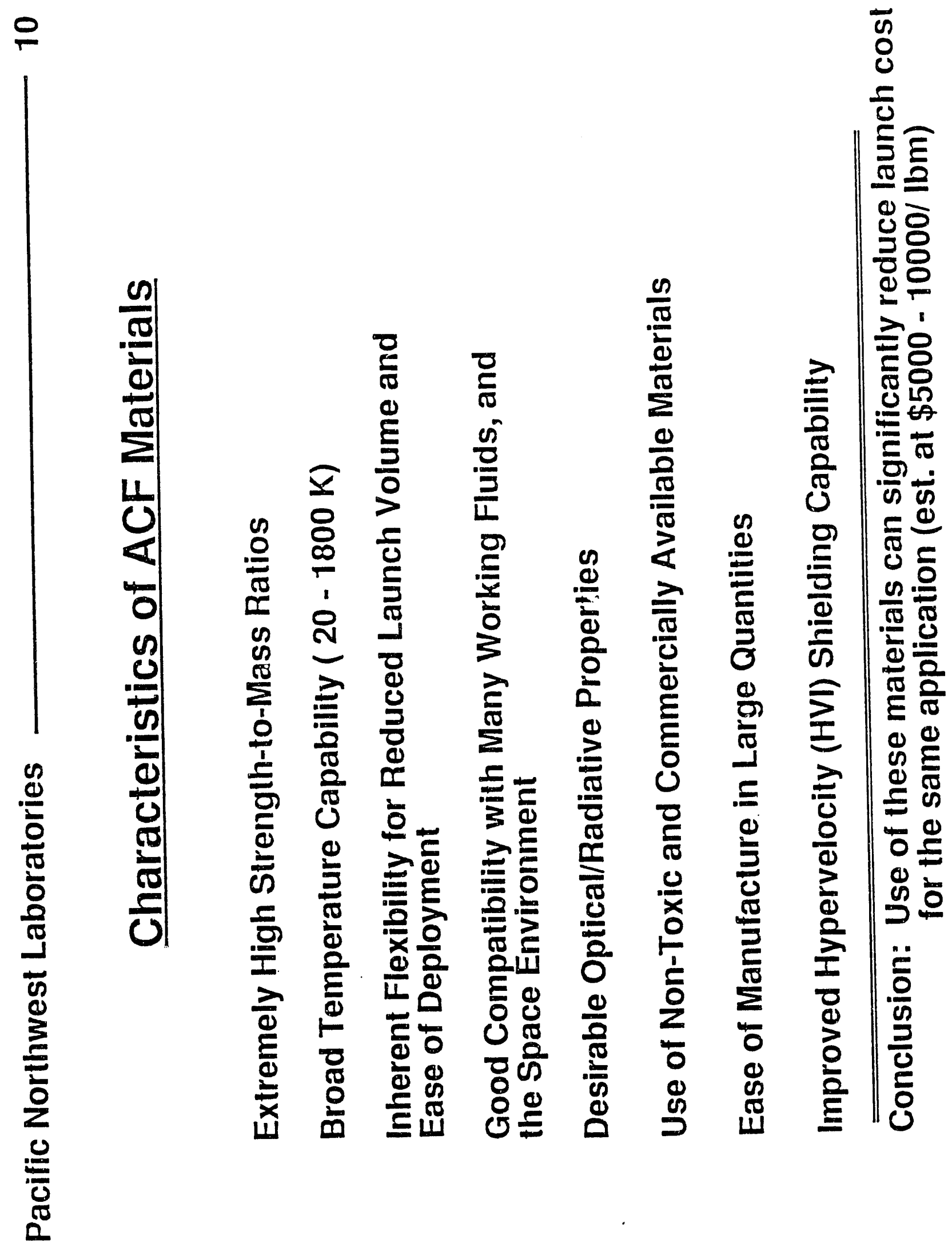




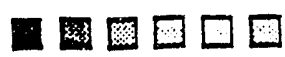

을

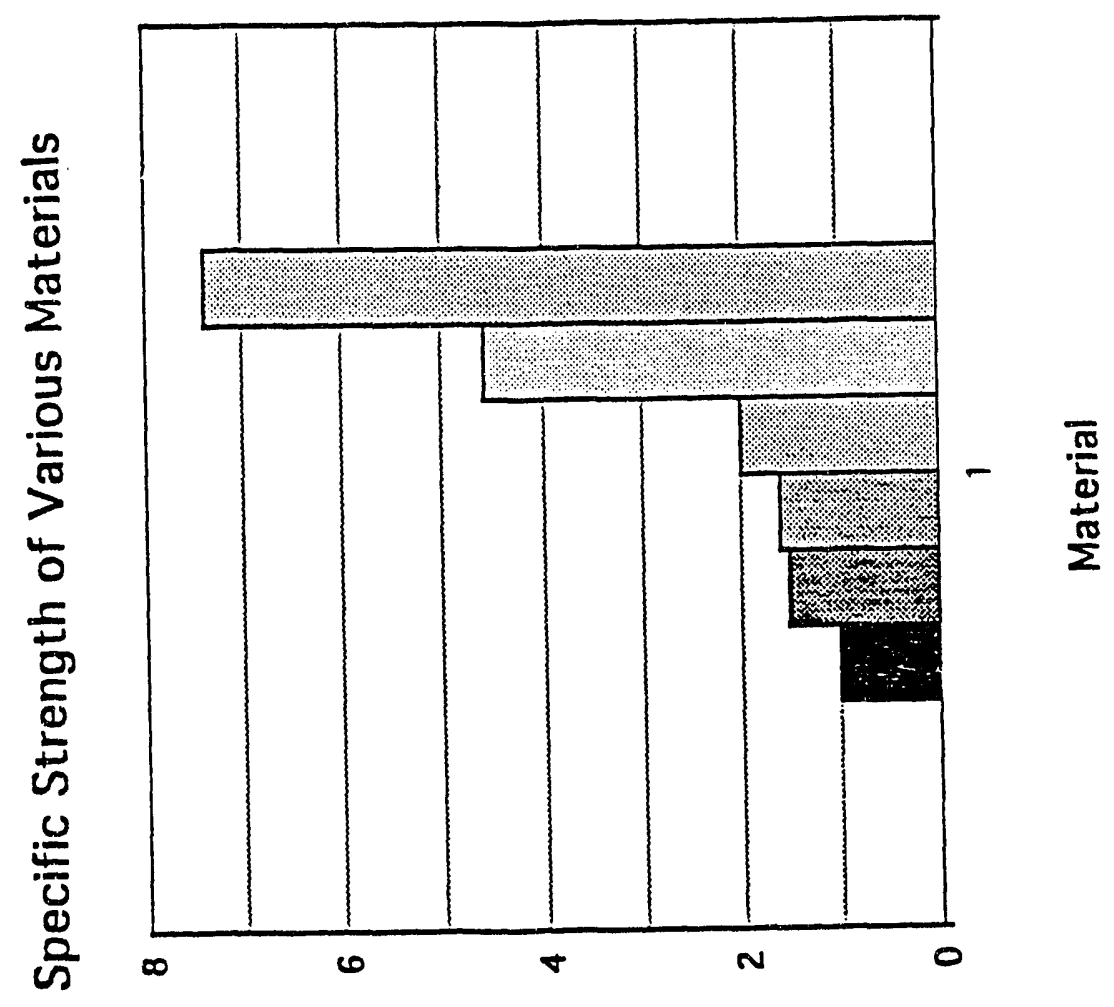

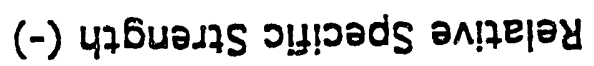

B. 11 

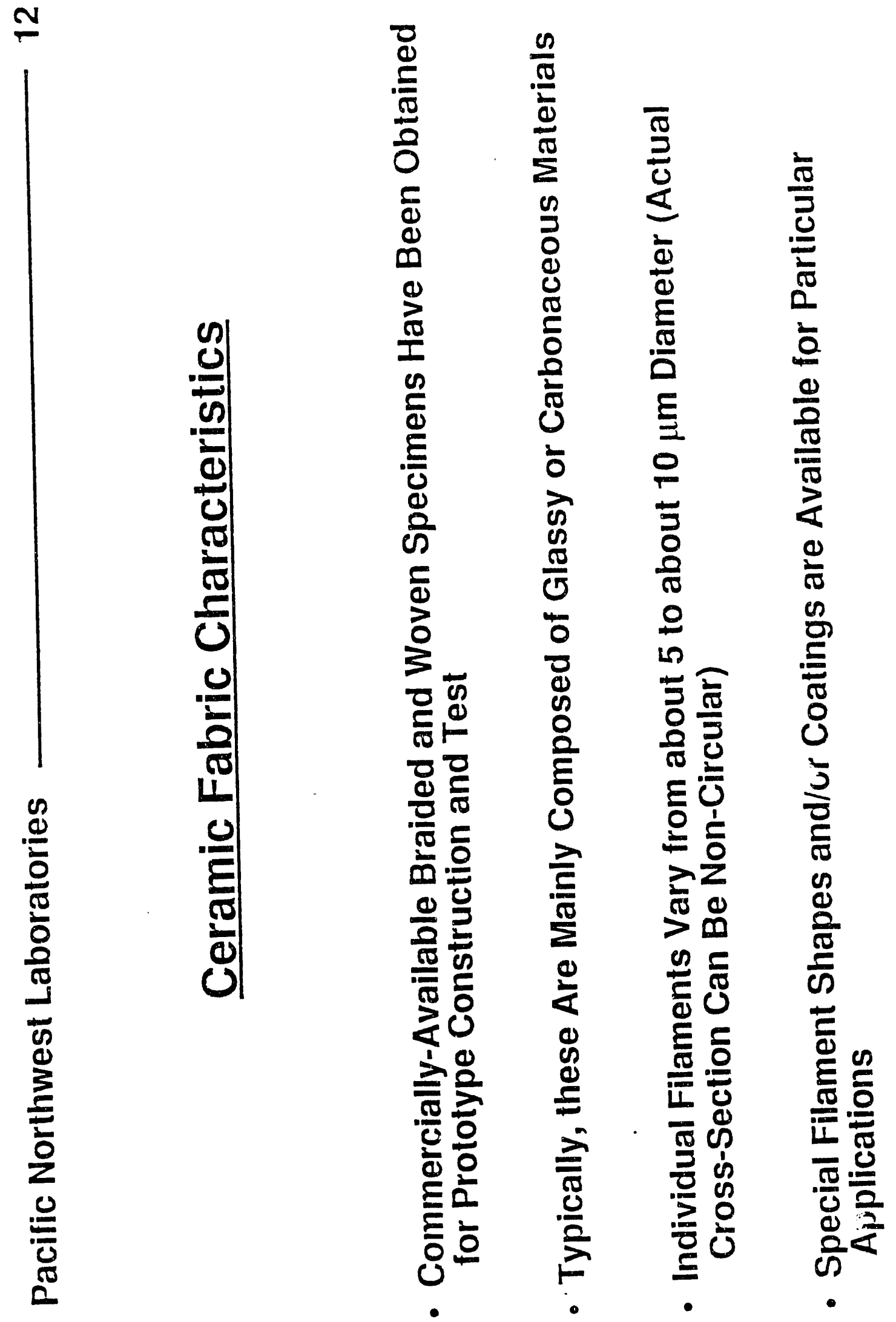

B. 12 

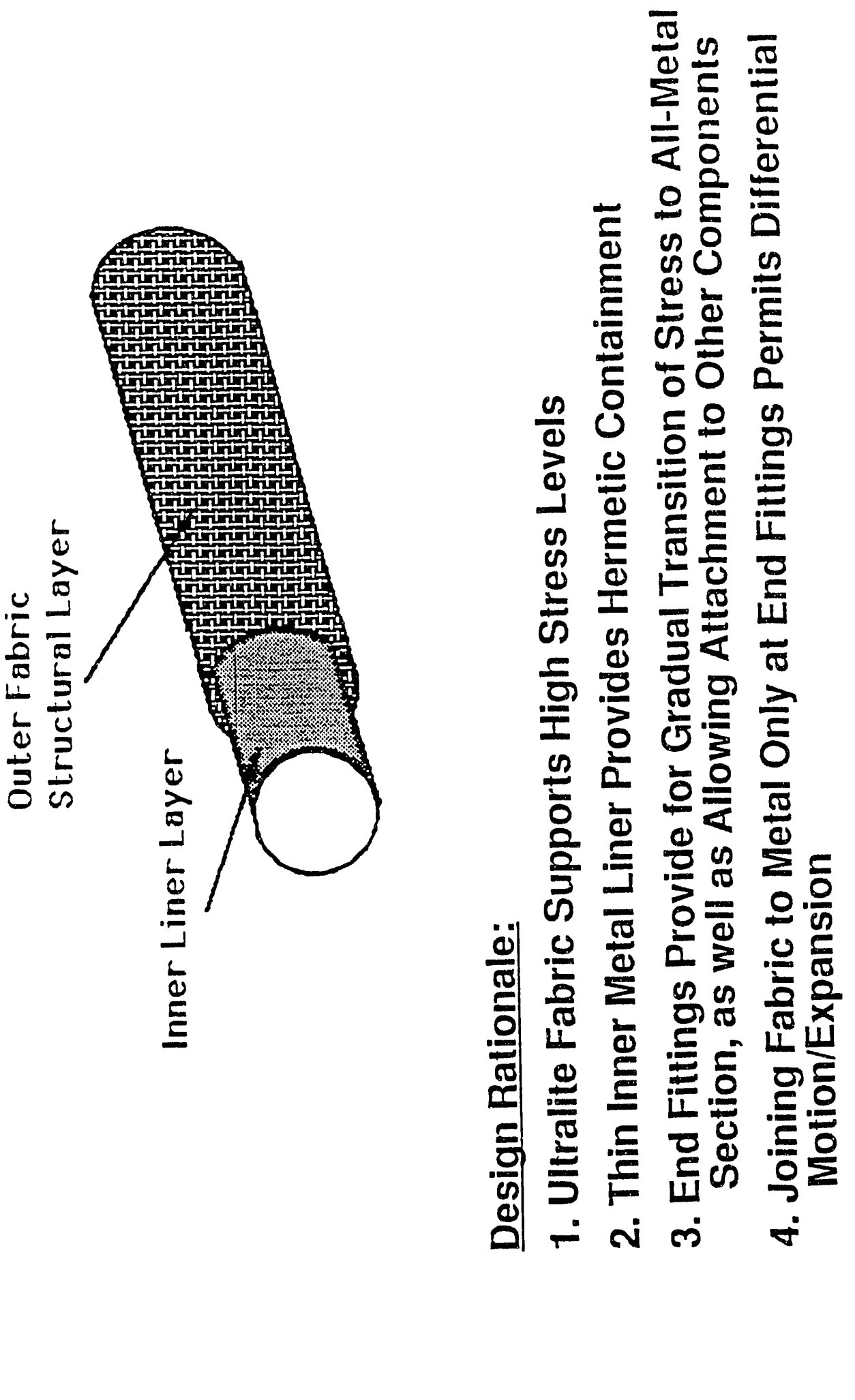

B. 13 


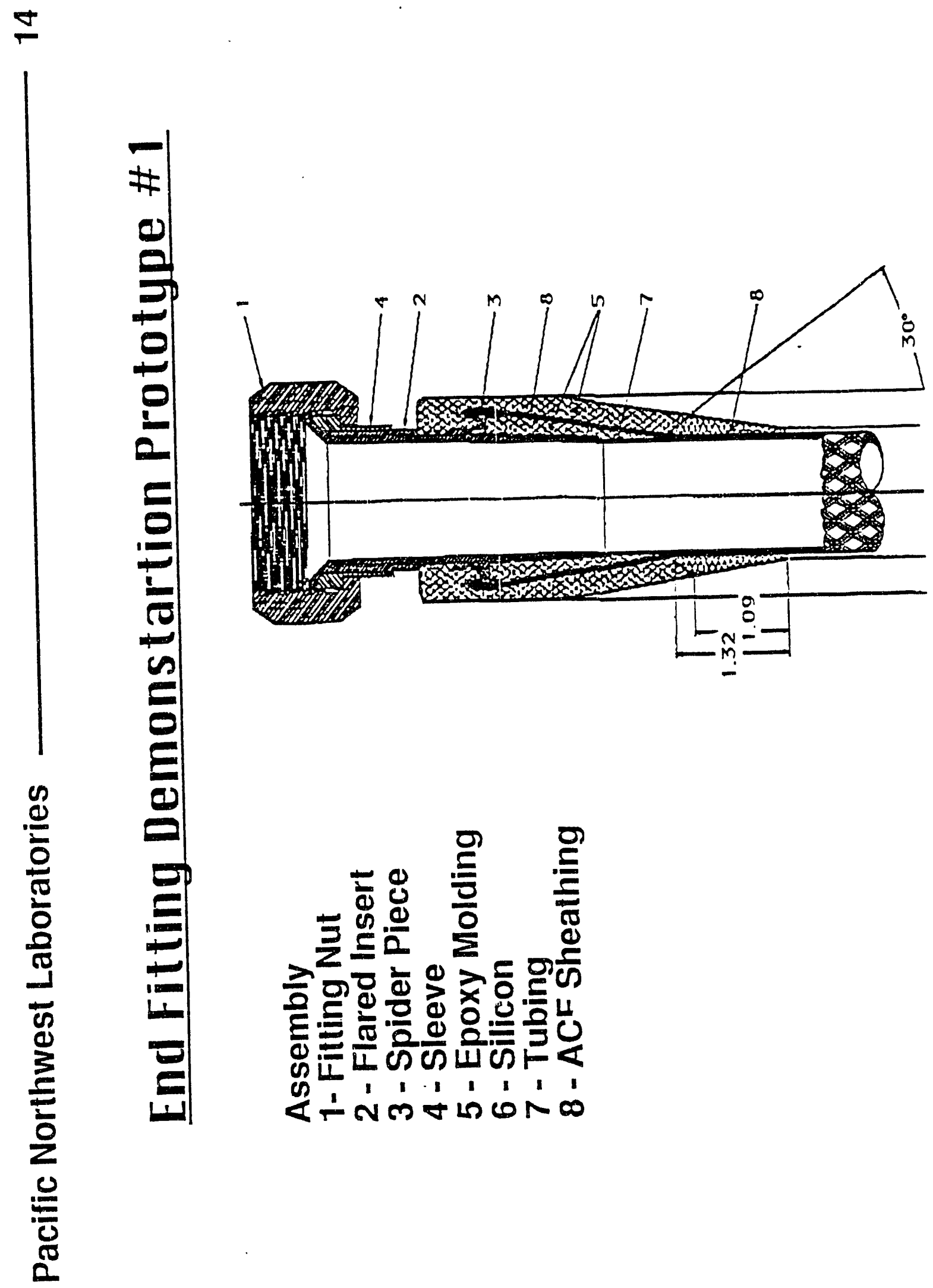

B. 14 


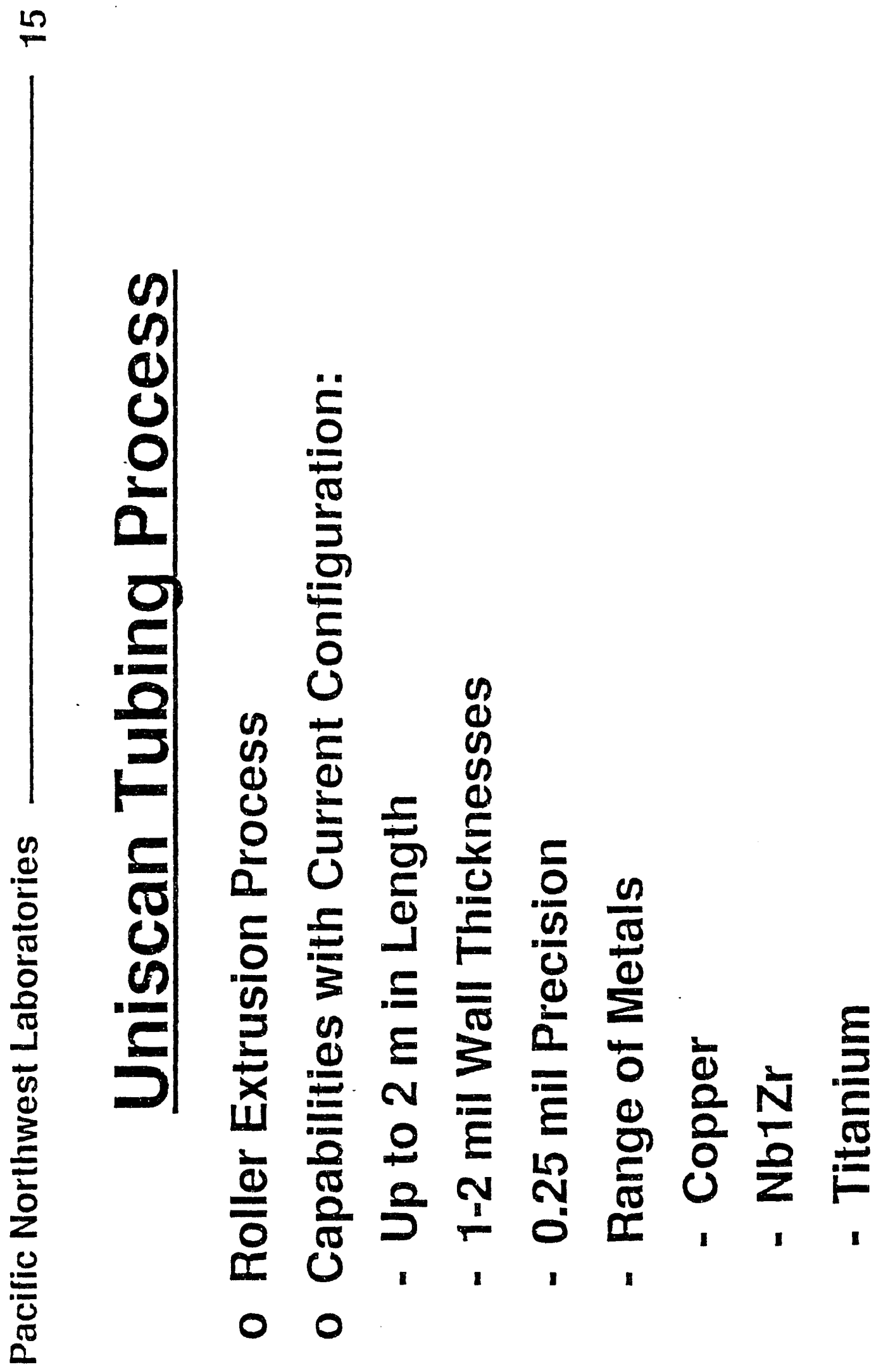

B. 15 


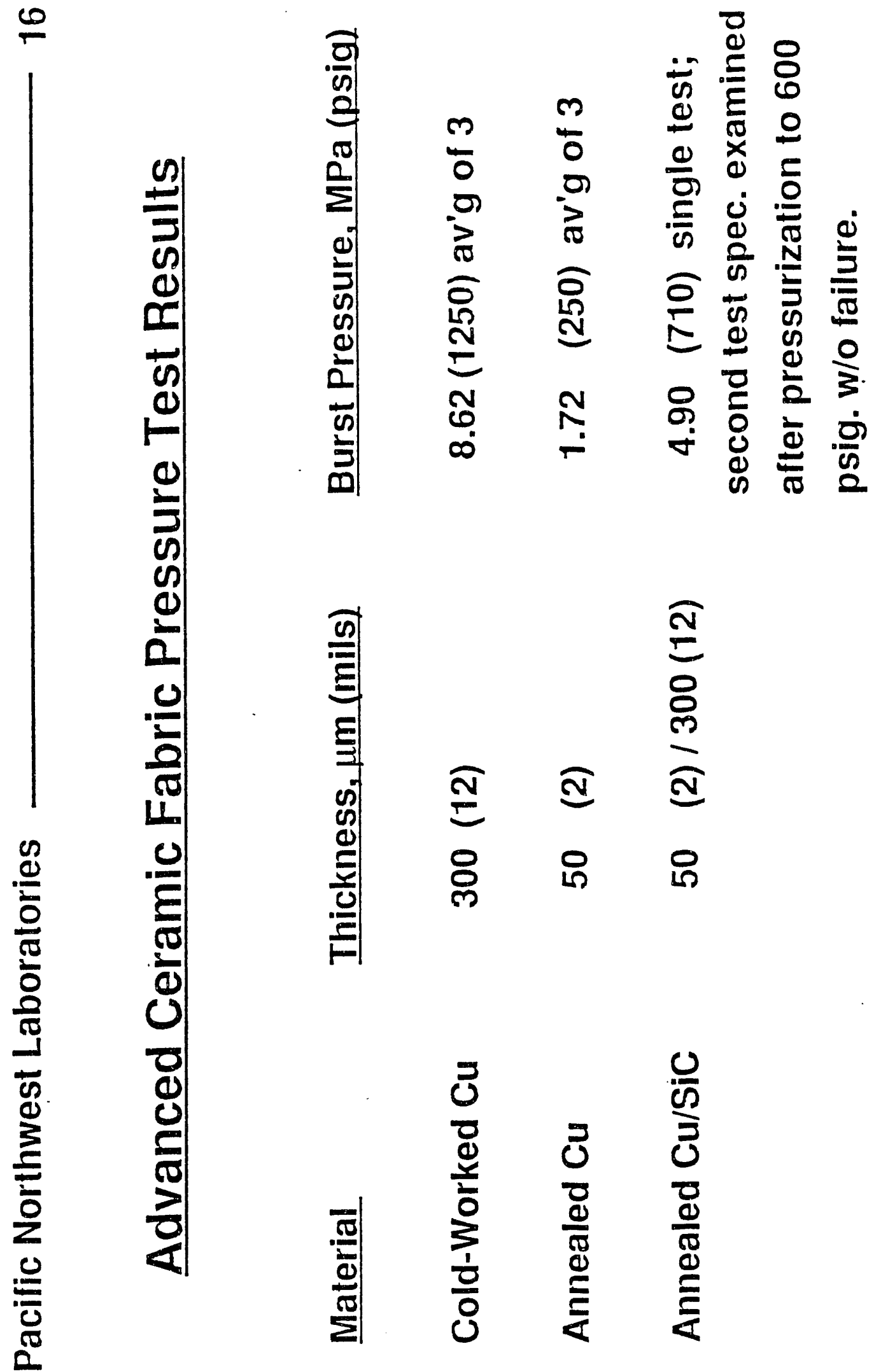

B. 16 


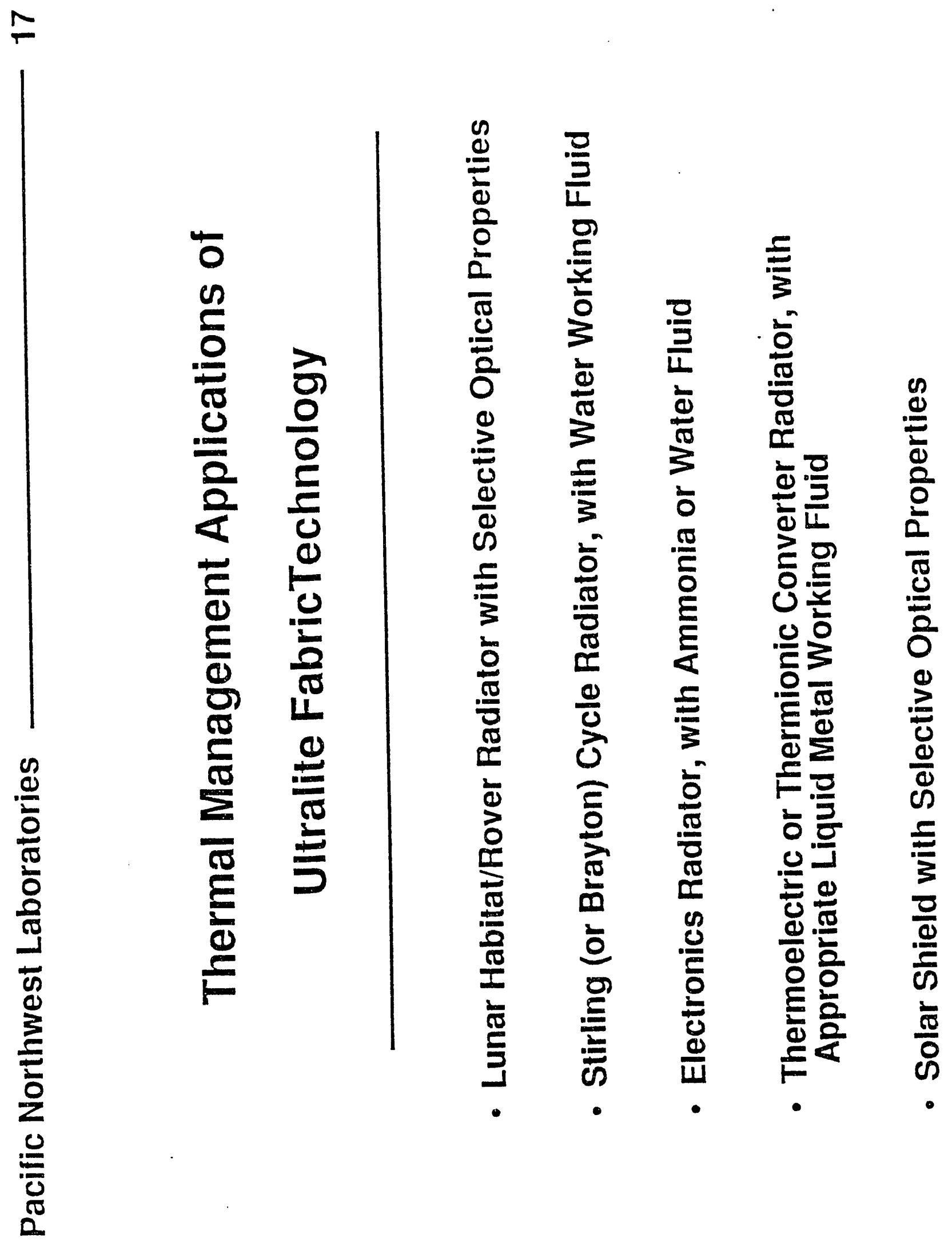




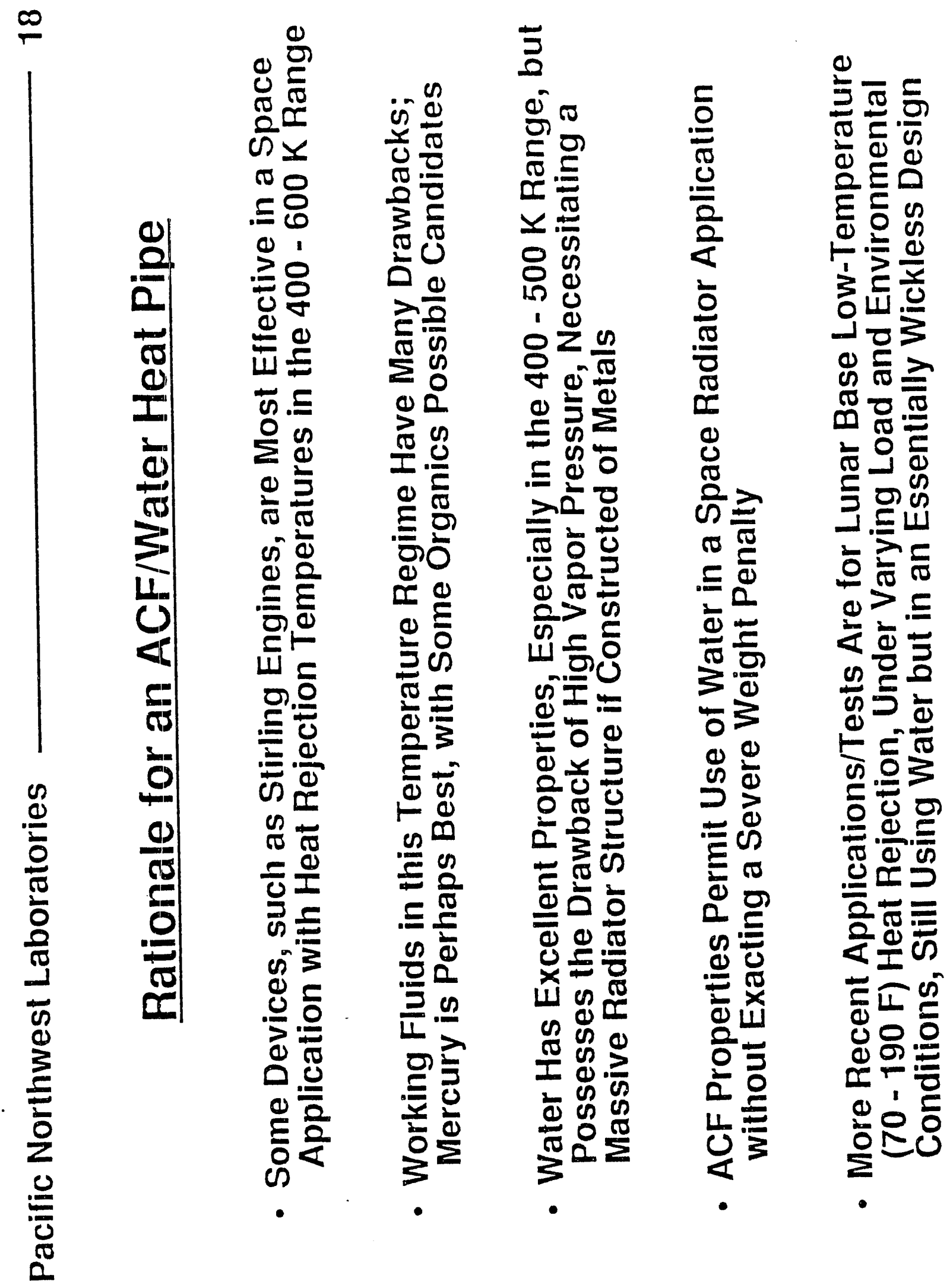


5

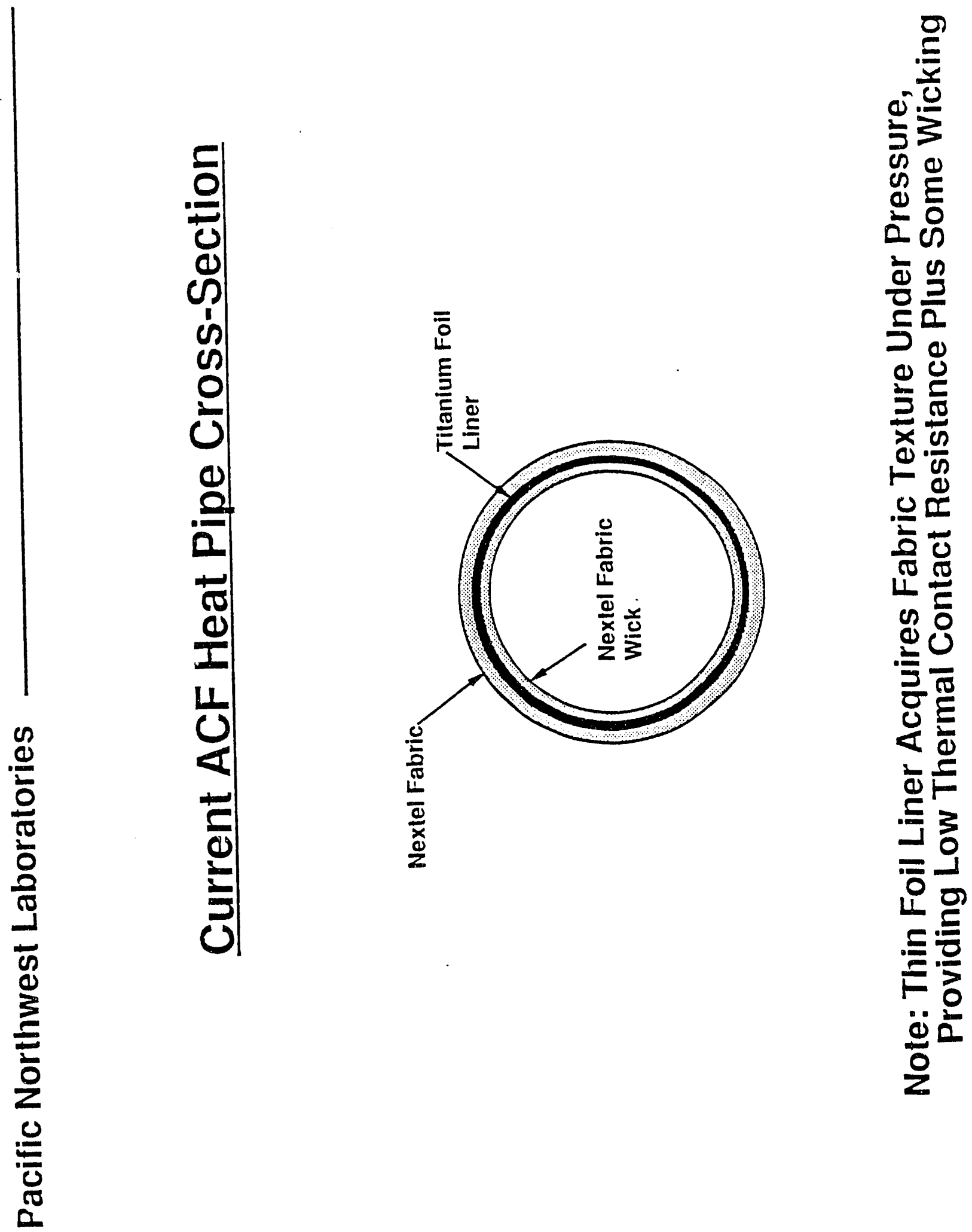

B. 19 

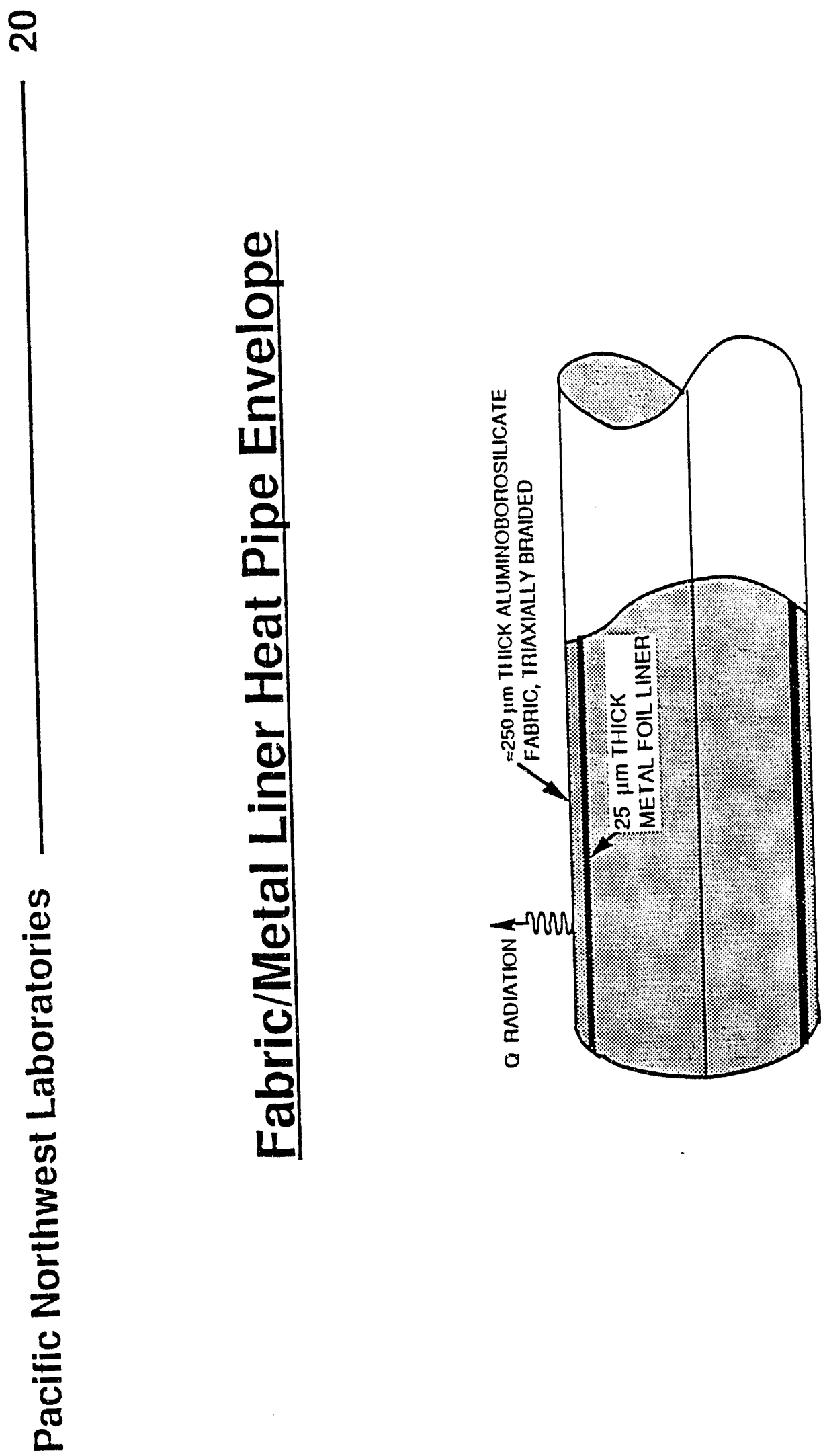


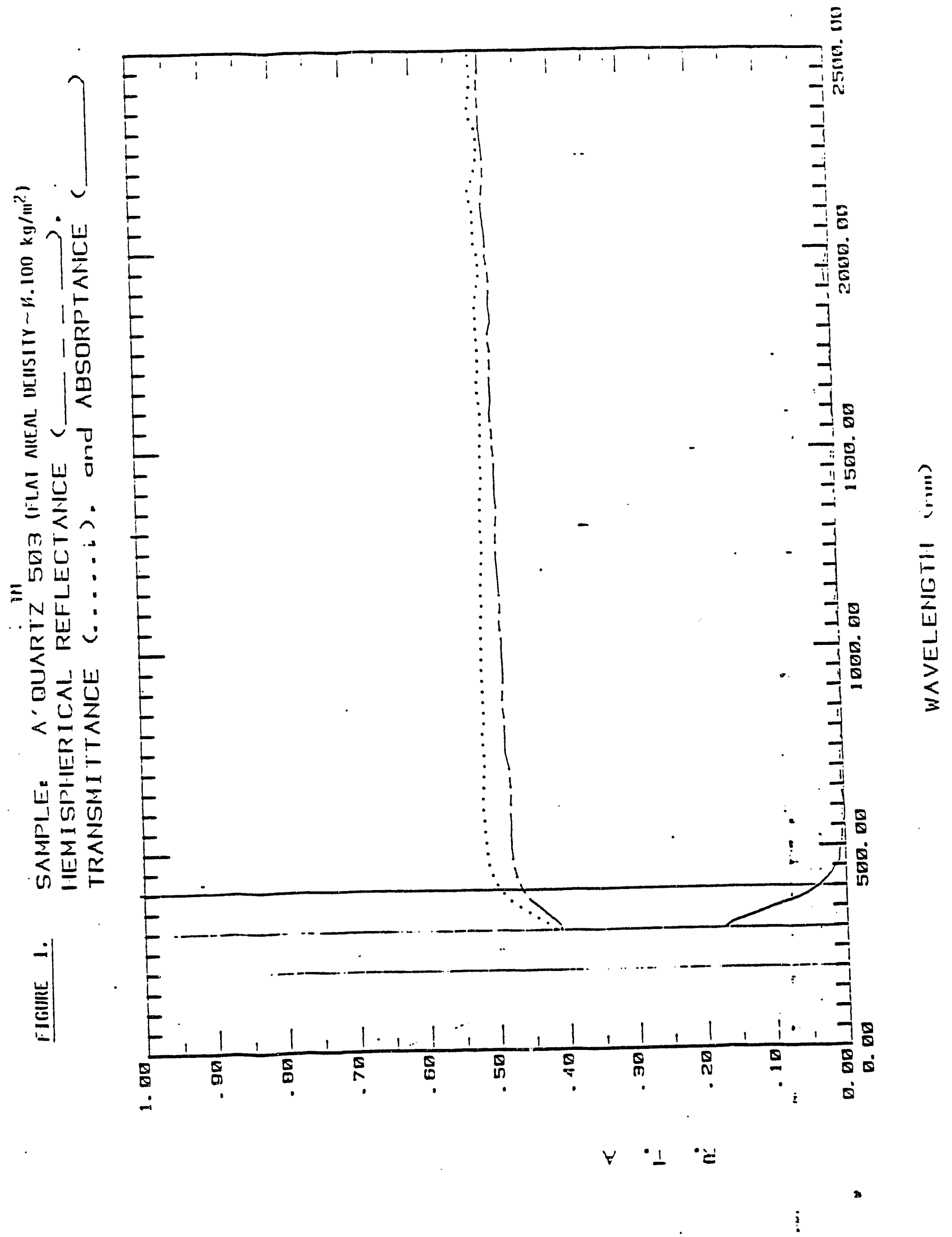




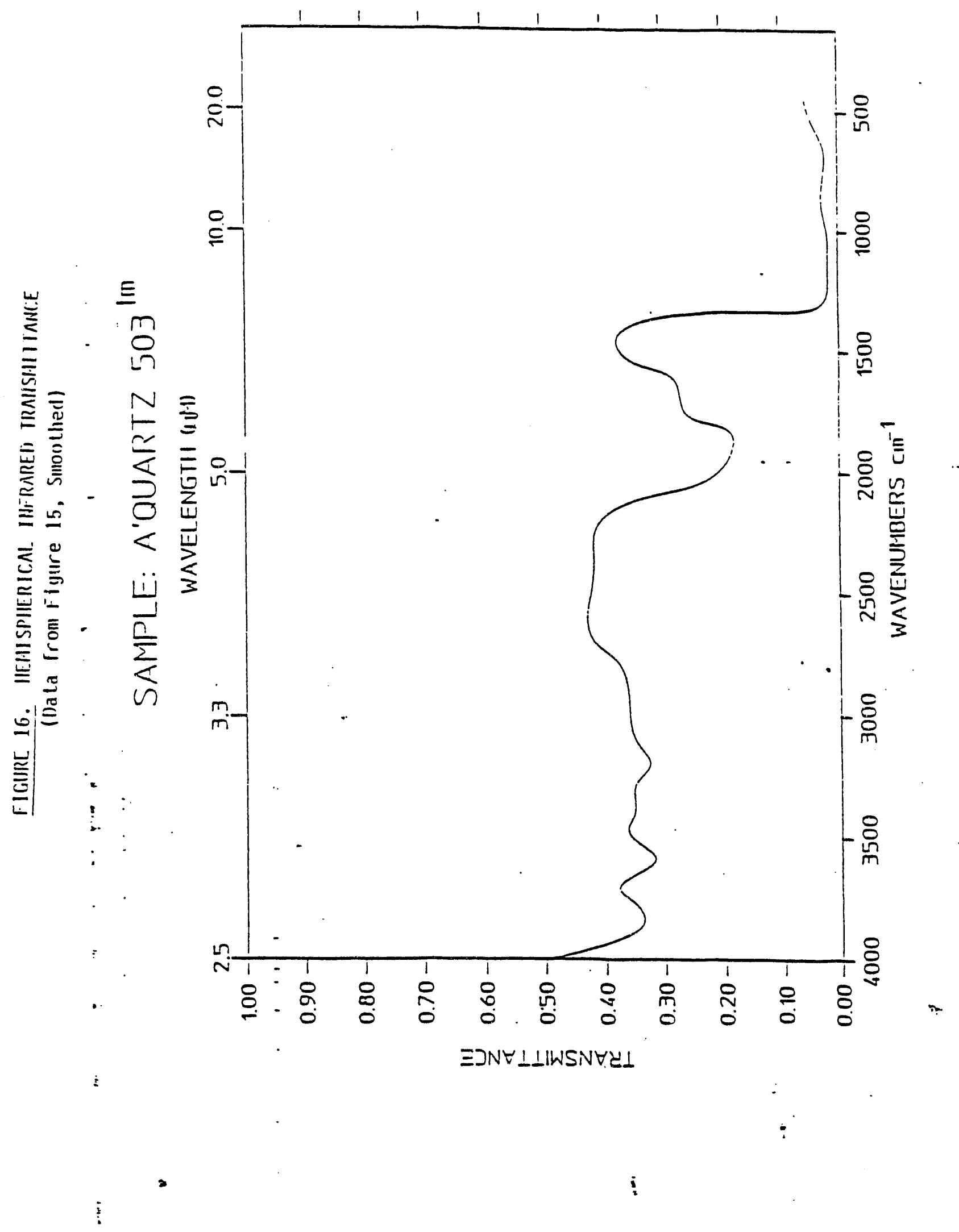

B. 22 


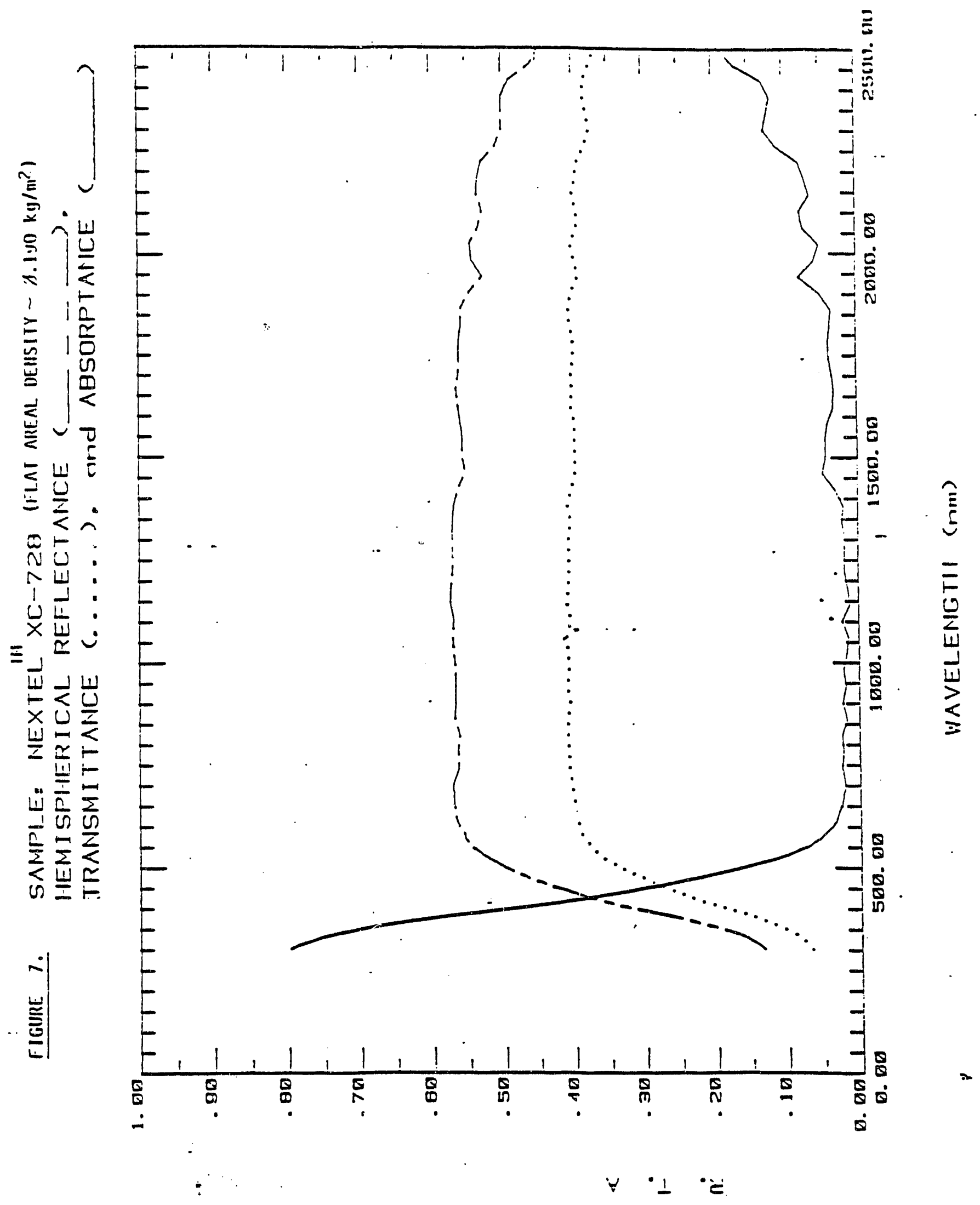




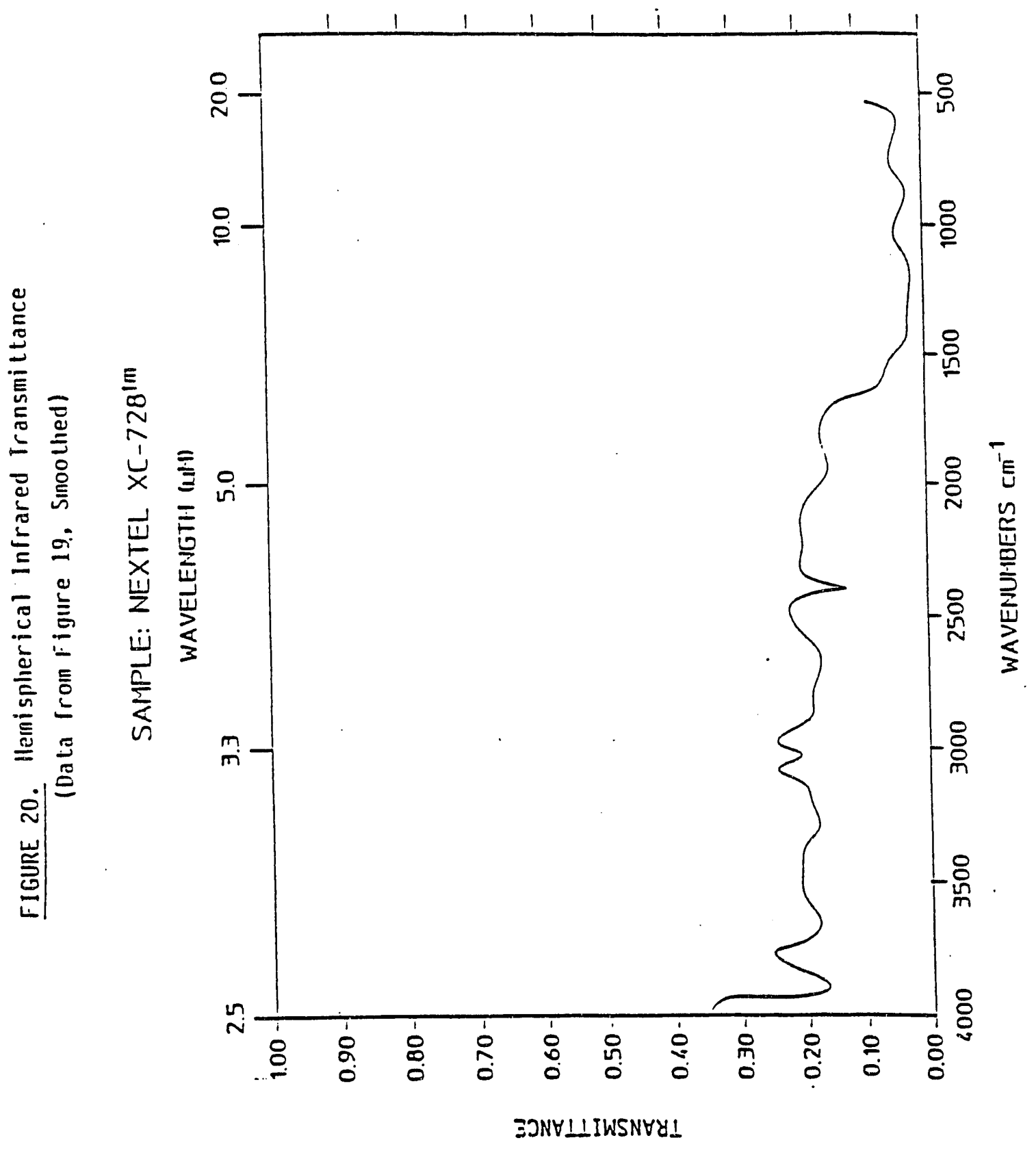


$\bar{N}$

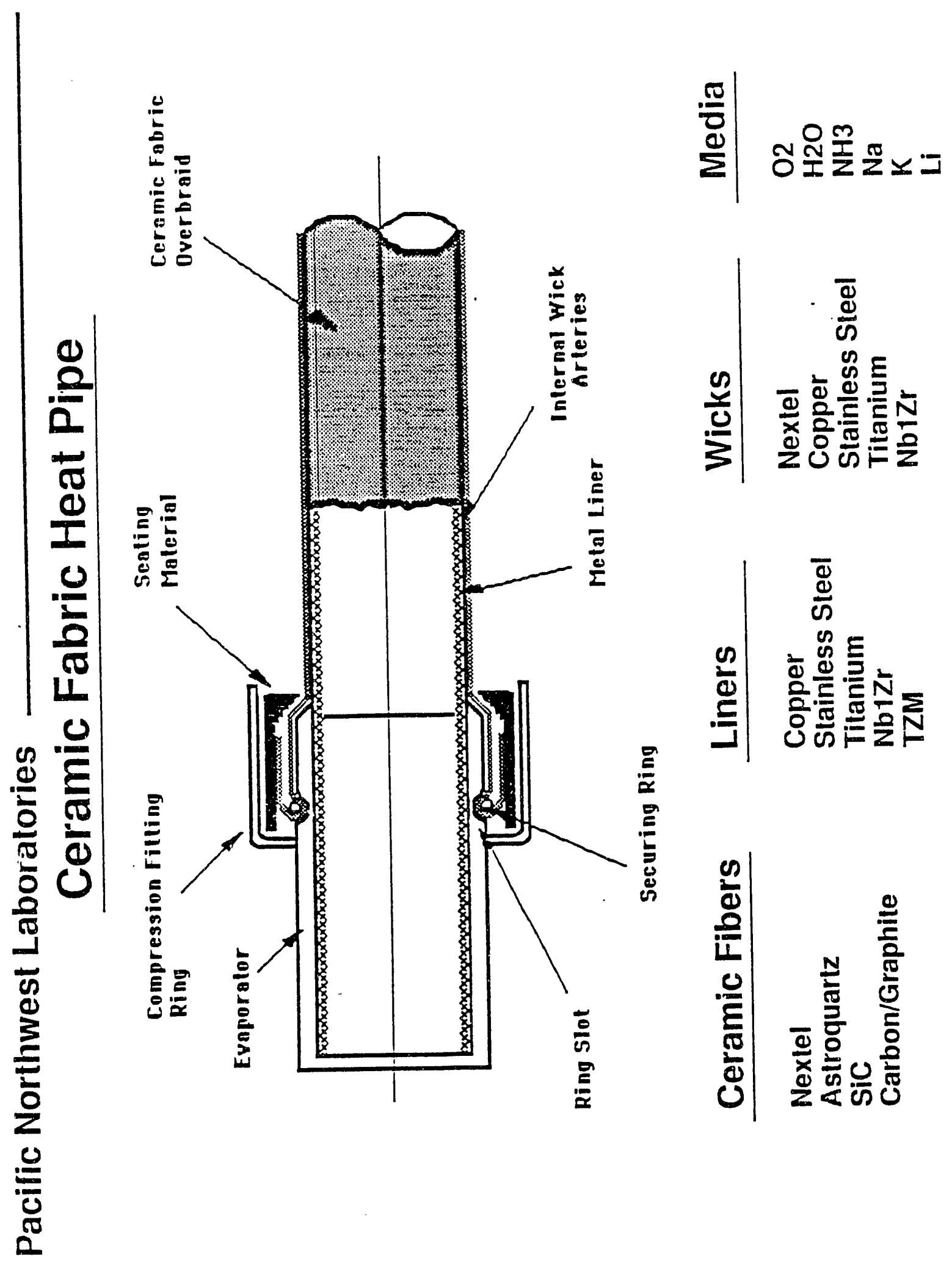


N

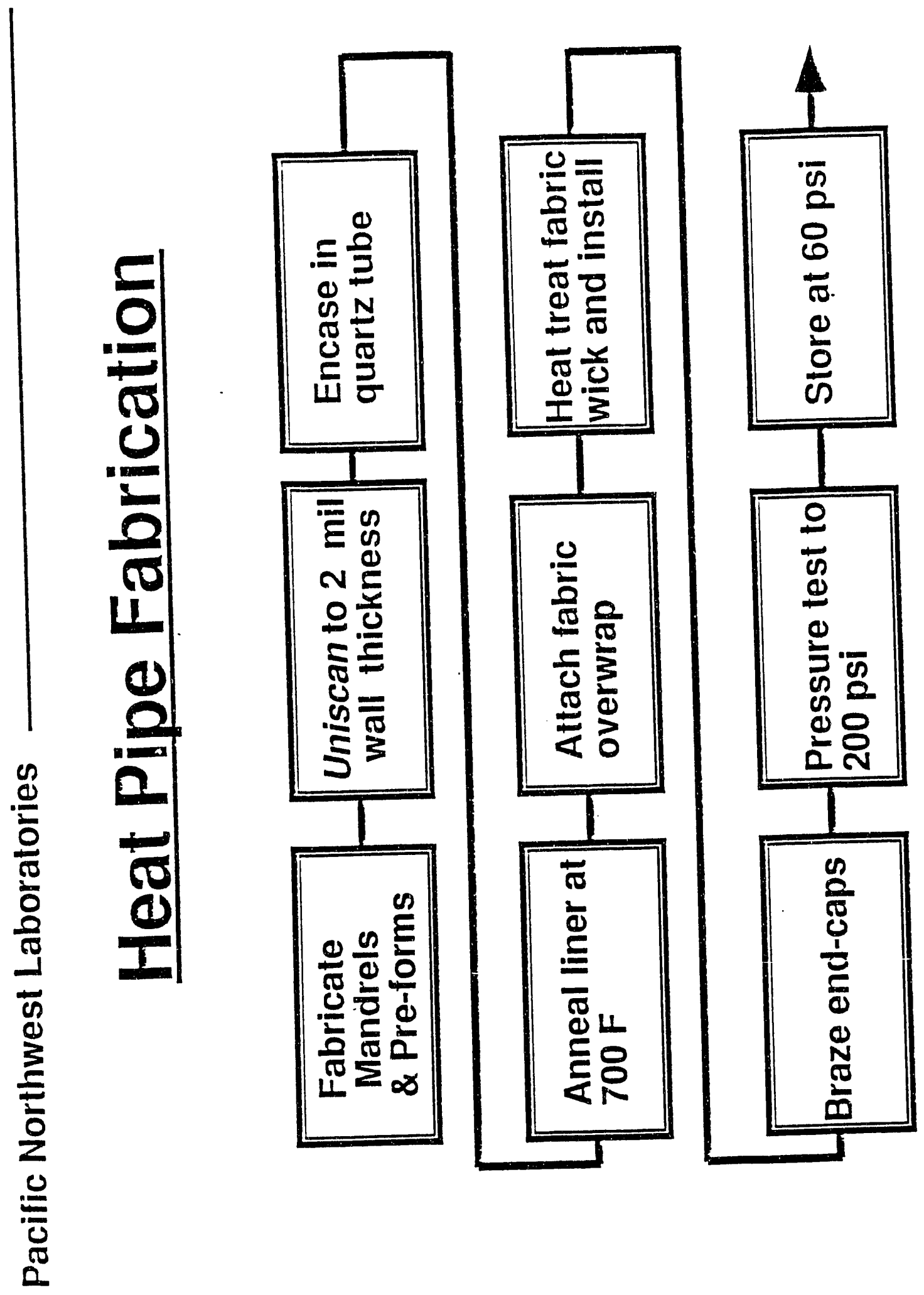


กิ

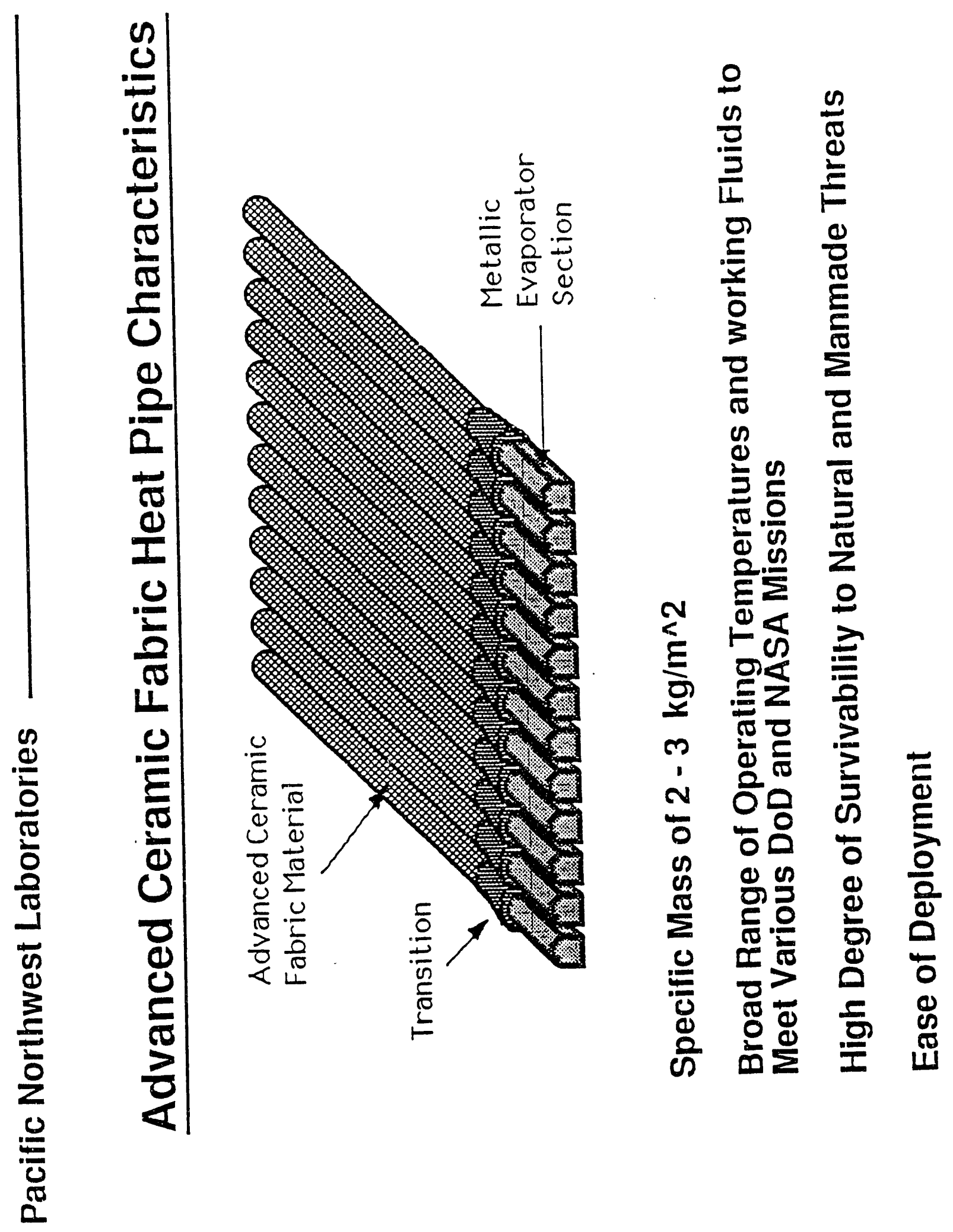




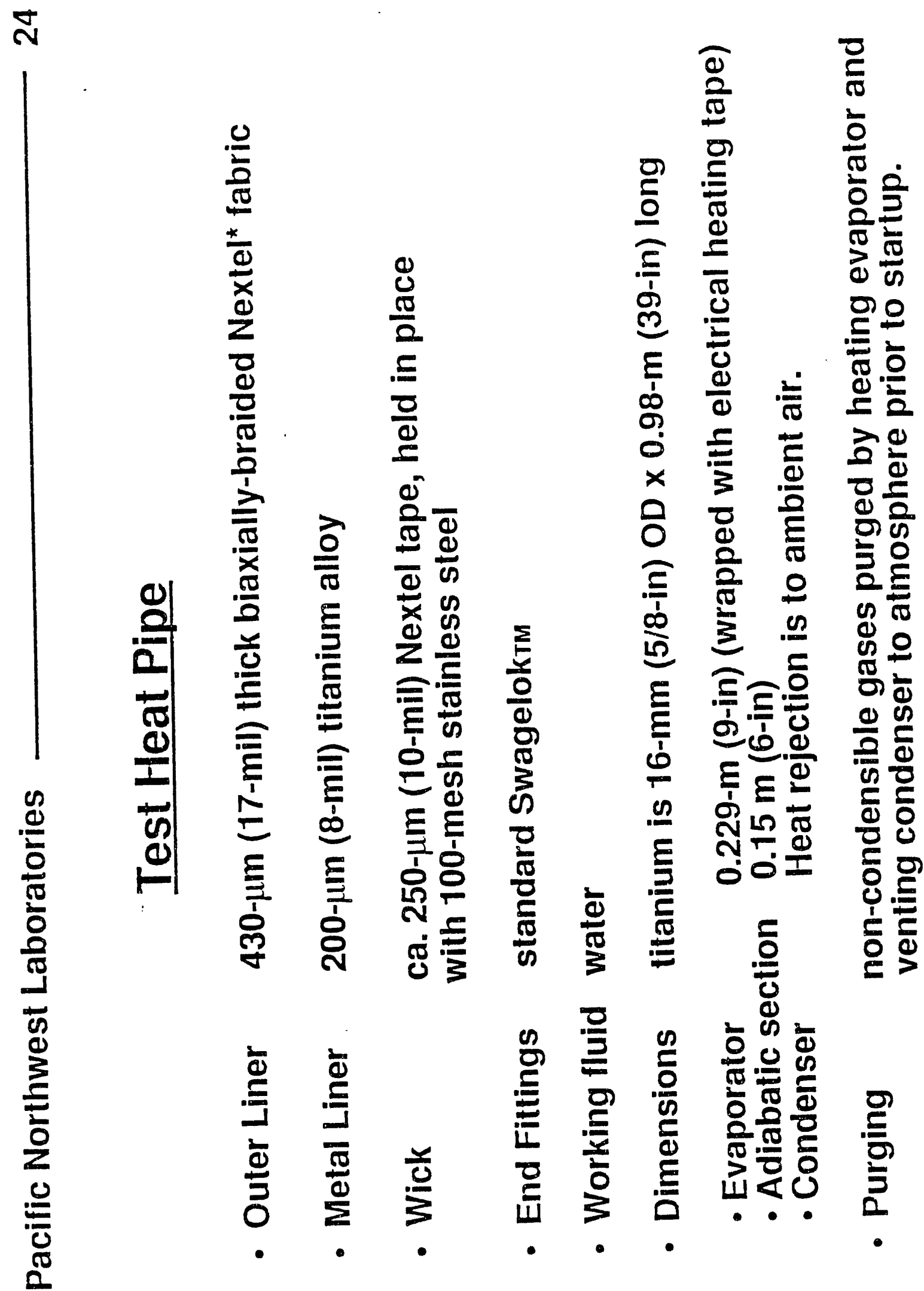


ㄴ

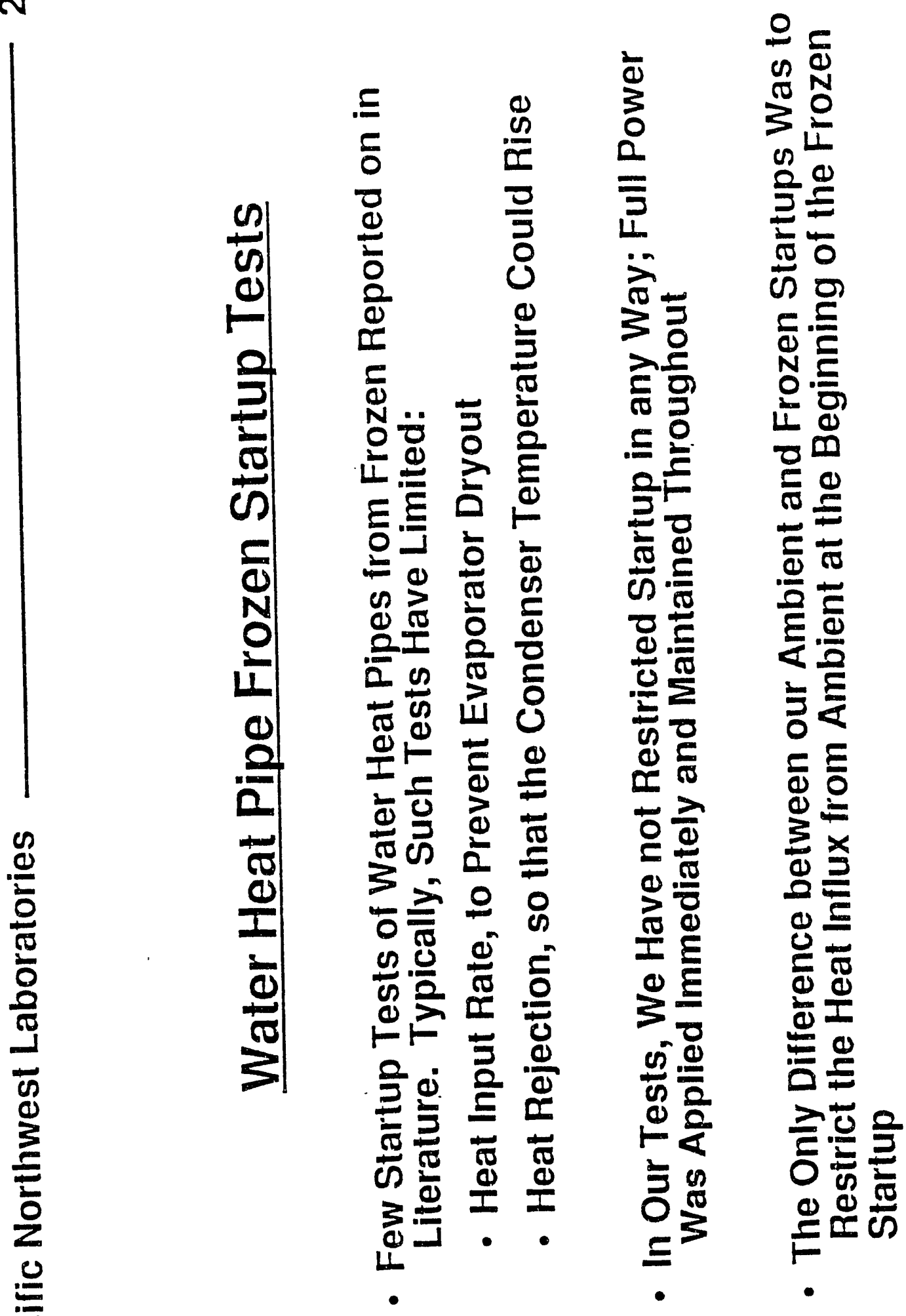




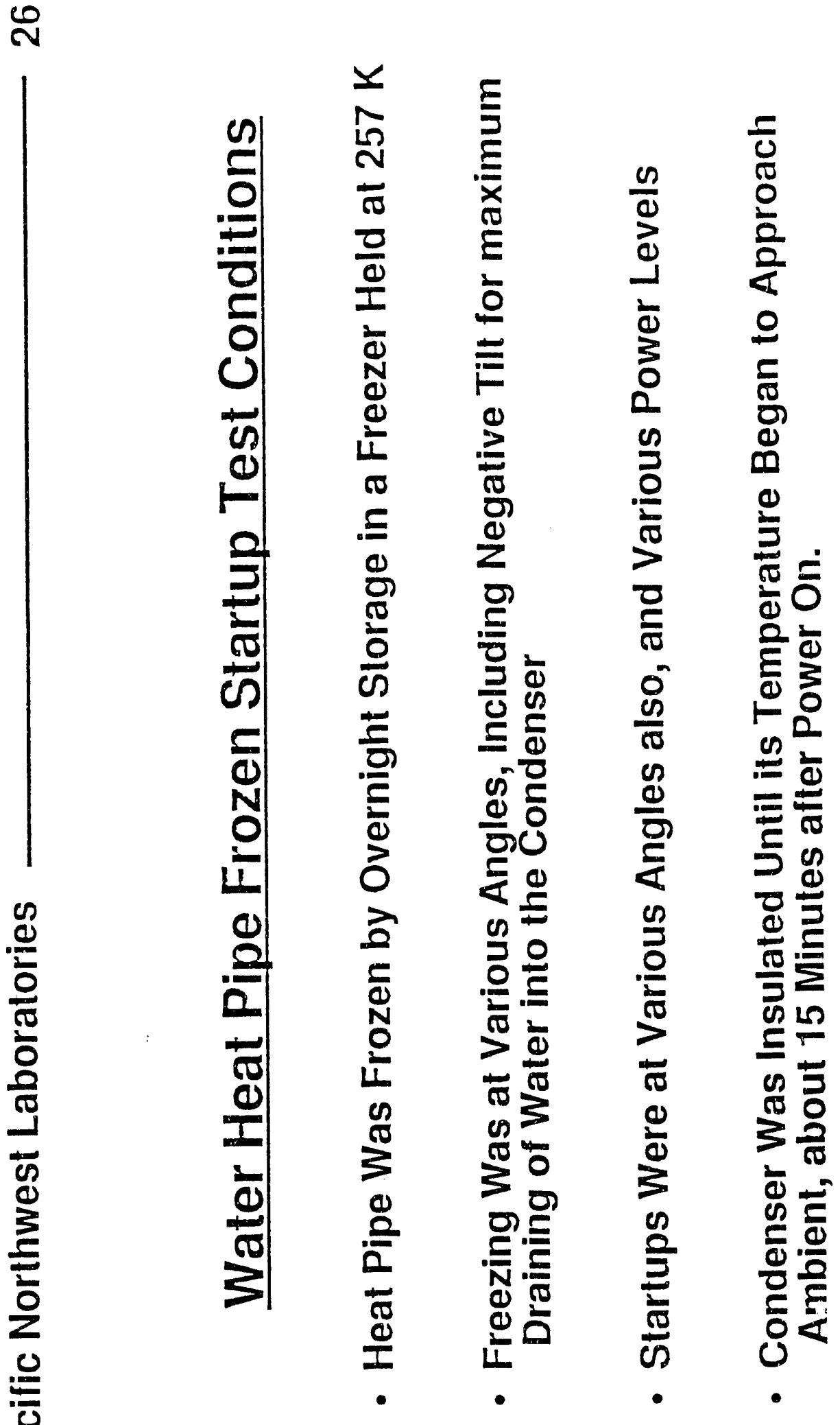




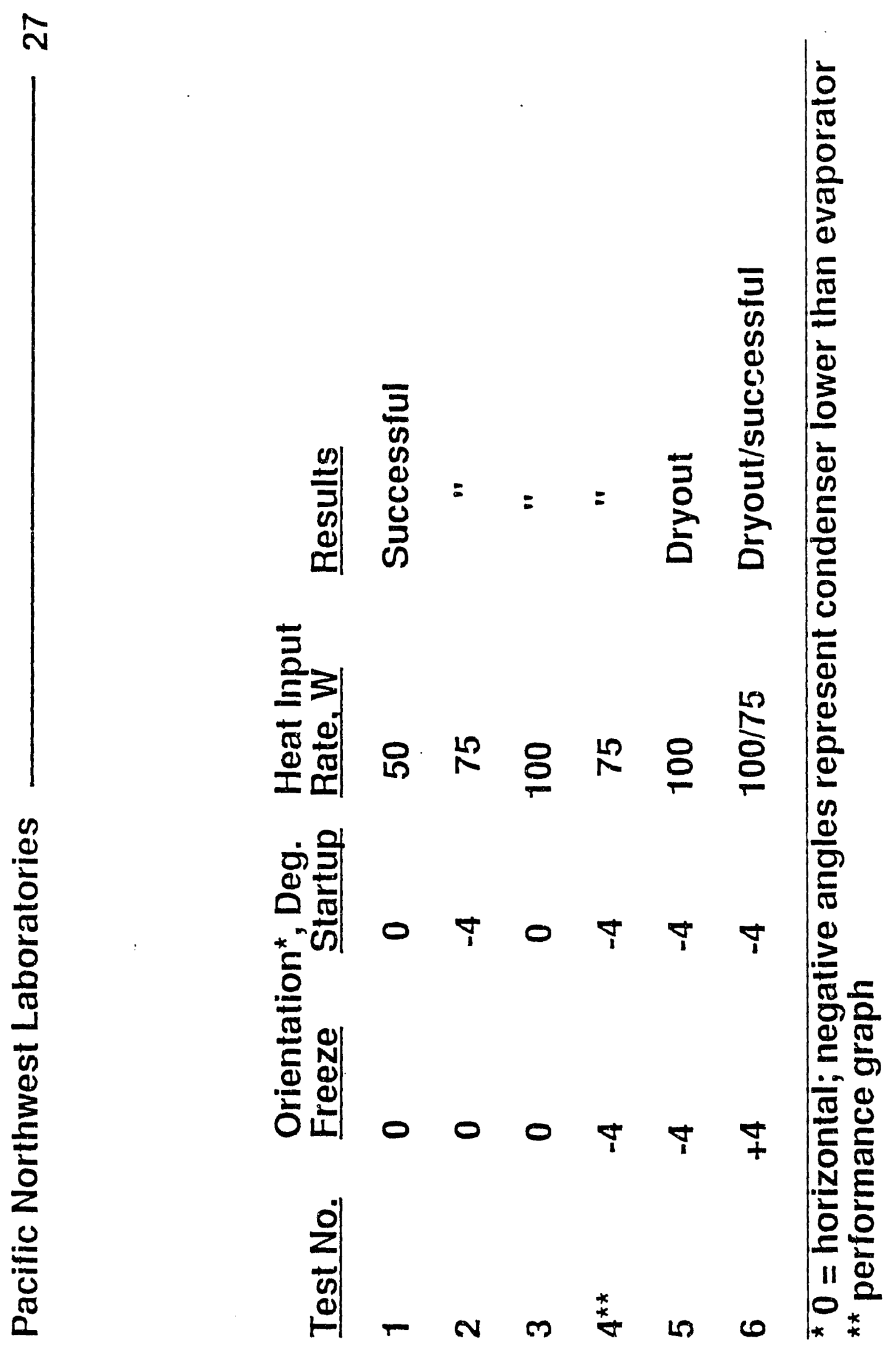

B.31 

ลิ

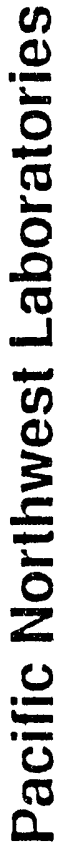
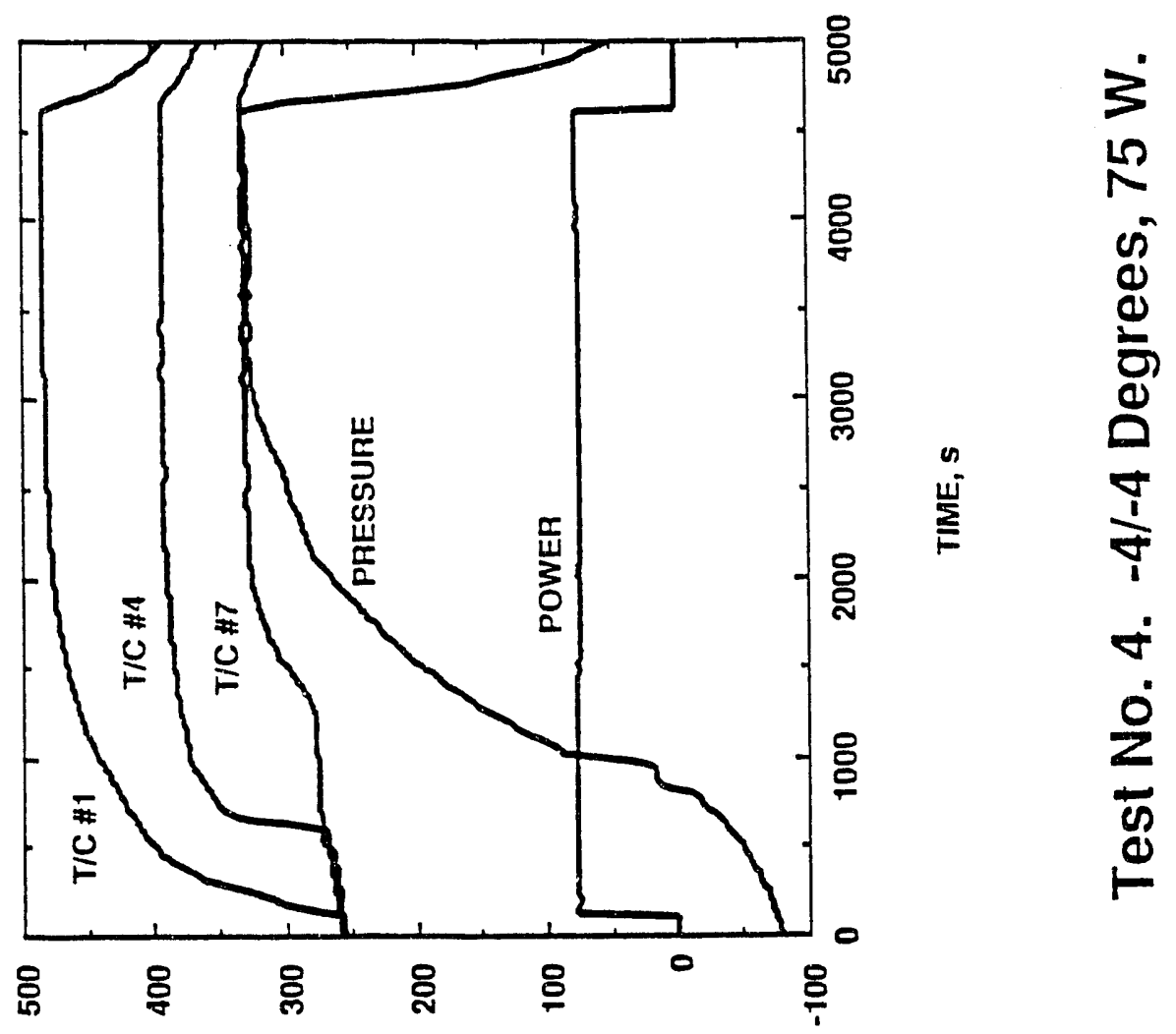

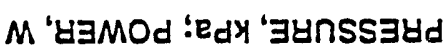

$x^{\prime} \exists \forall \cap \perp \forall \forall \exists d W \exists \perp$ 
요

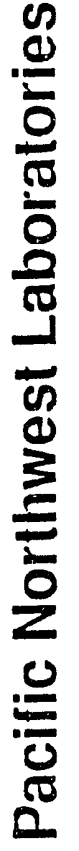

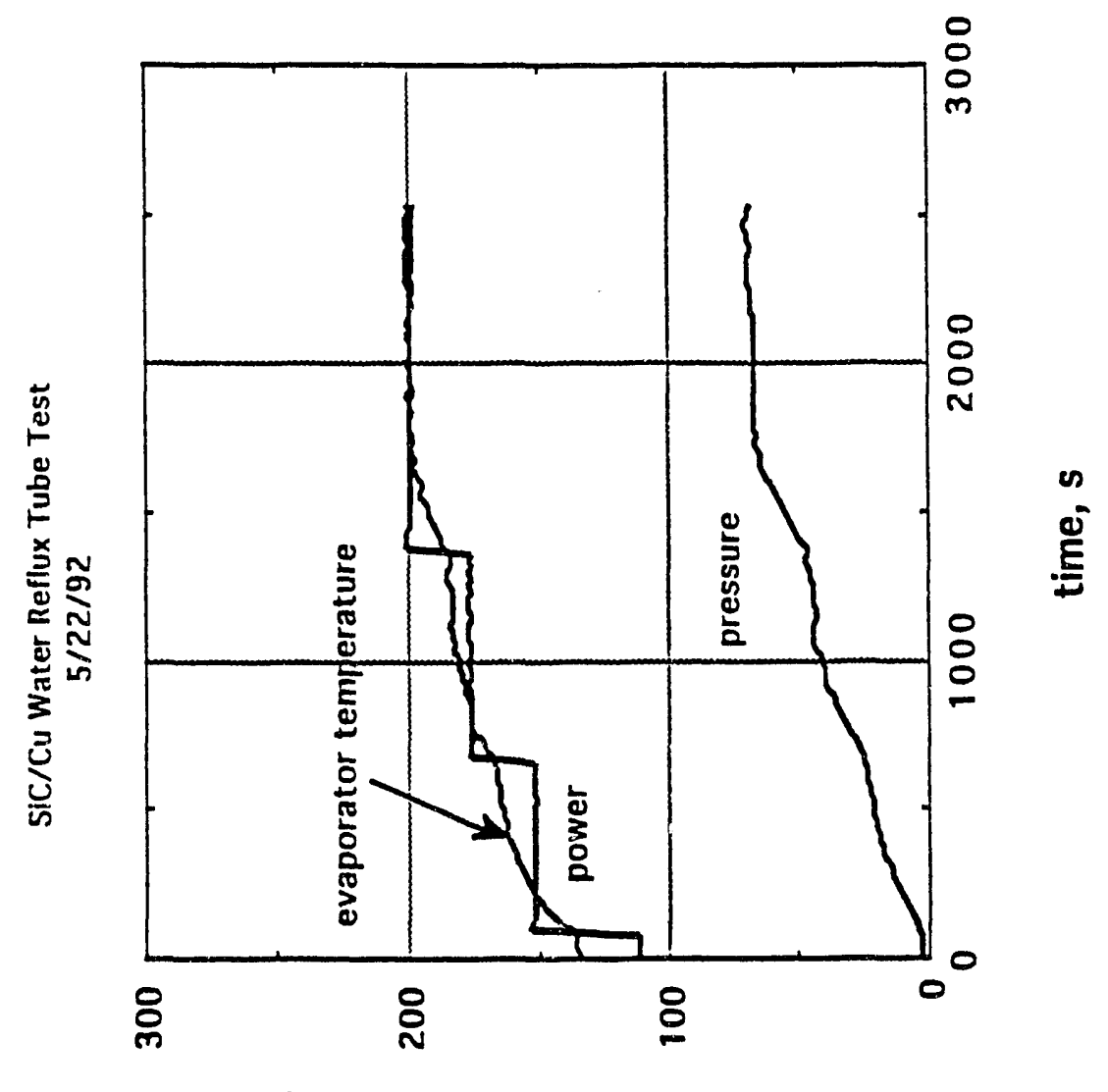

6!sd do 's77eM '5 "6ap

B.34 


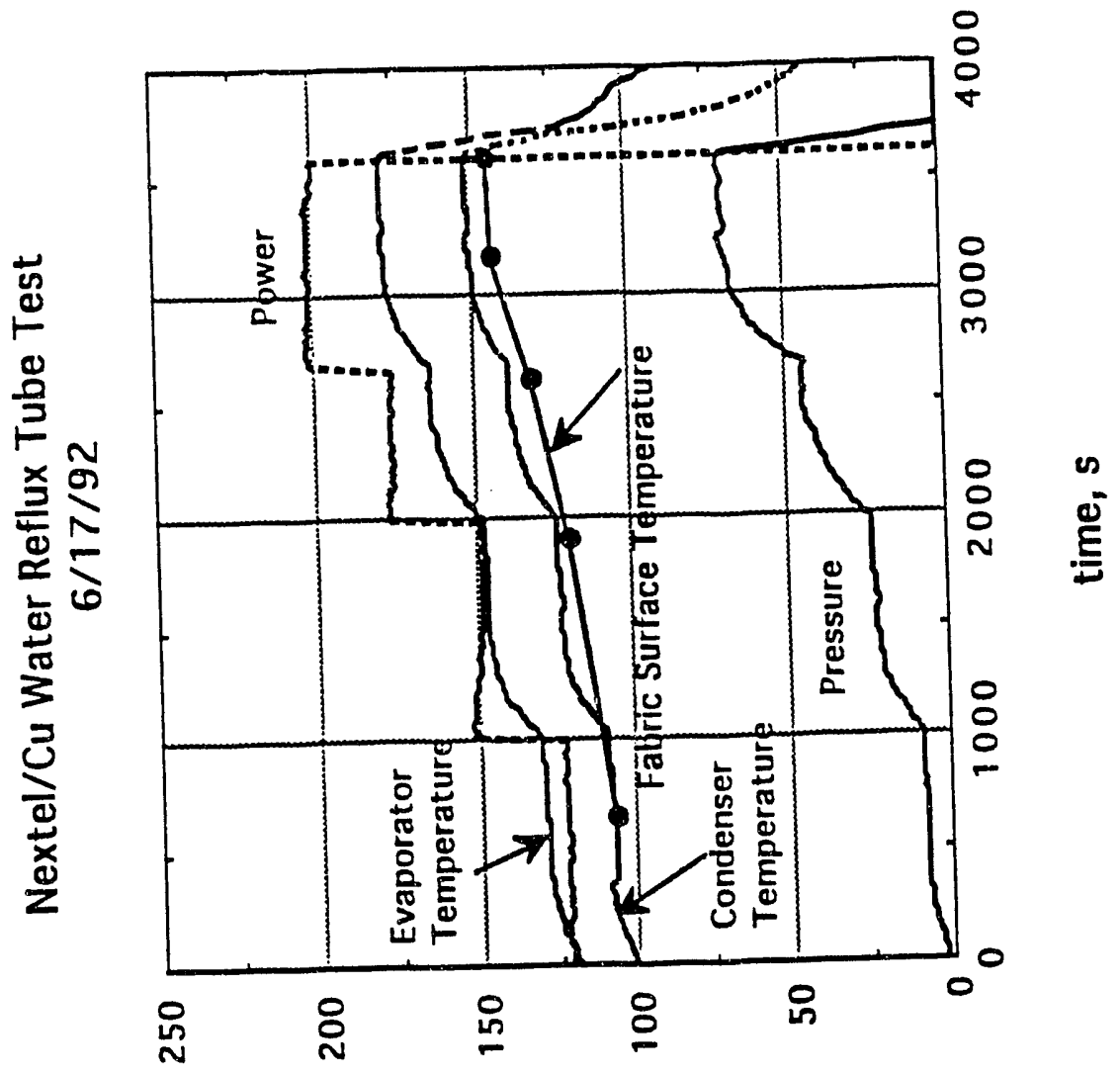

6!sd 10 ‘s77eM ' 5 -6әp 
స్

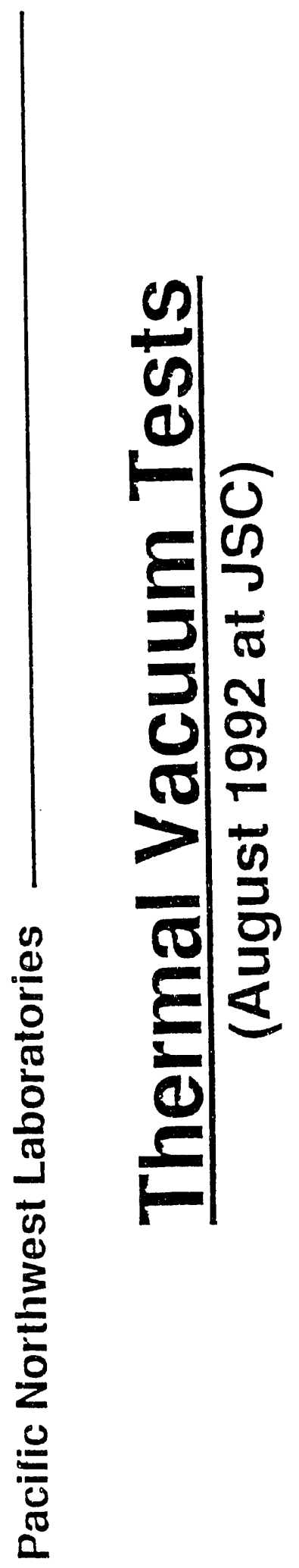

$\frac{\frac{2}{0}}{\frac{\pi}{\frac{\pi}{2}}}$

\&

$\pi$

m

离

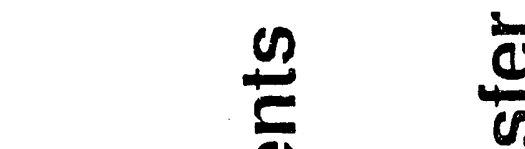

क ल क ल क

I

2. $\frac{0}{2}=$

2

$x \geqslant 0 \geqslant 010$

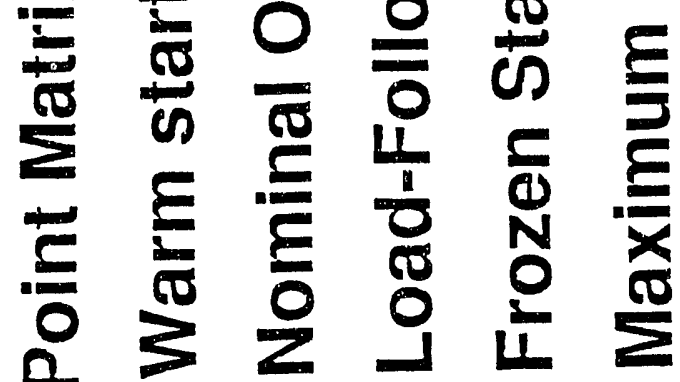

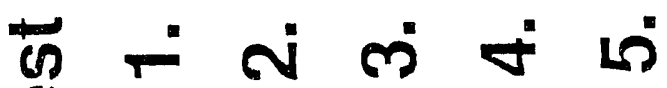

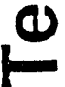


n






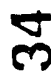

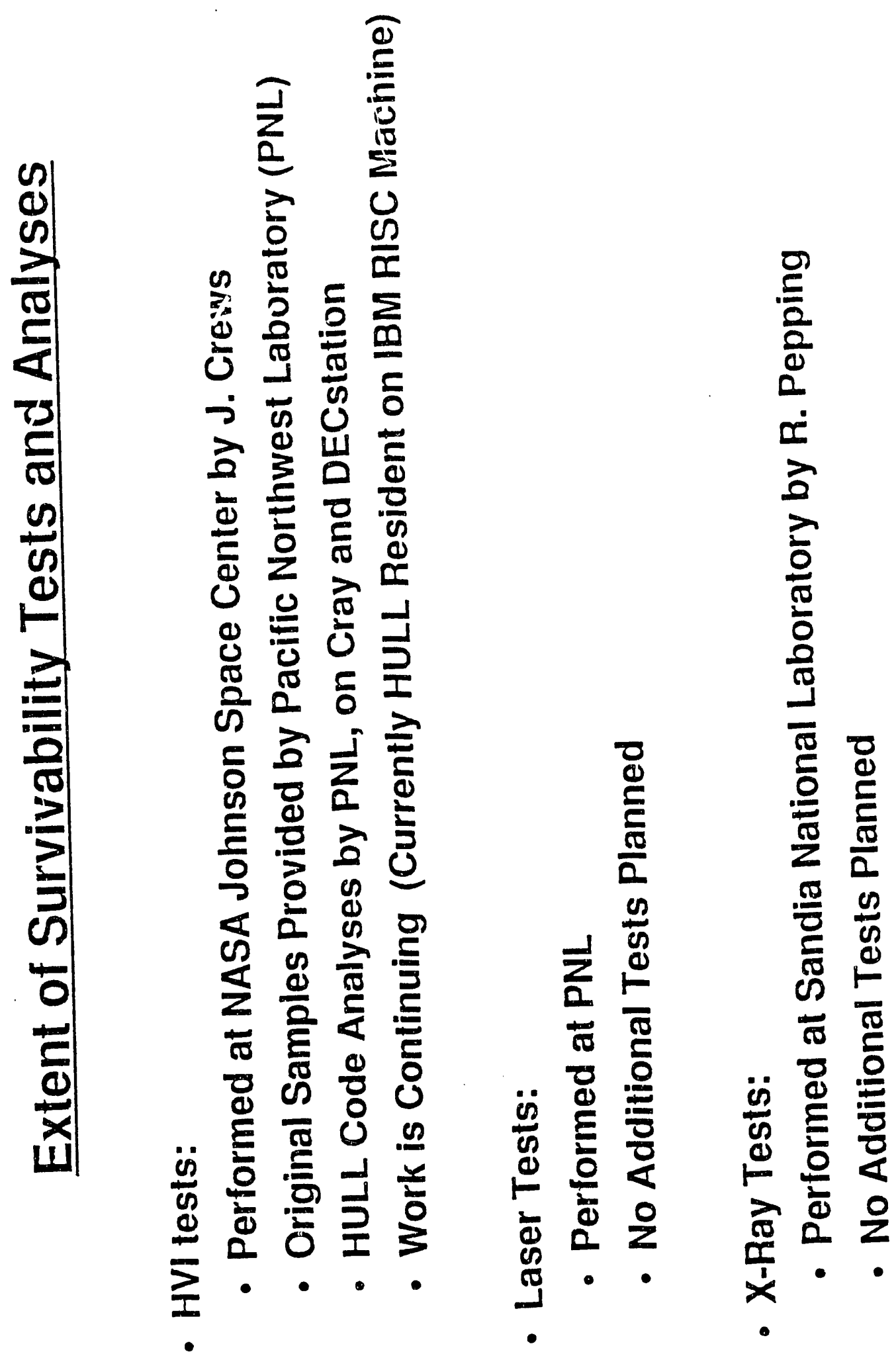




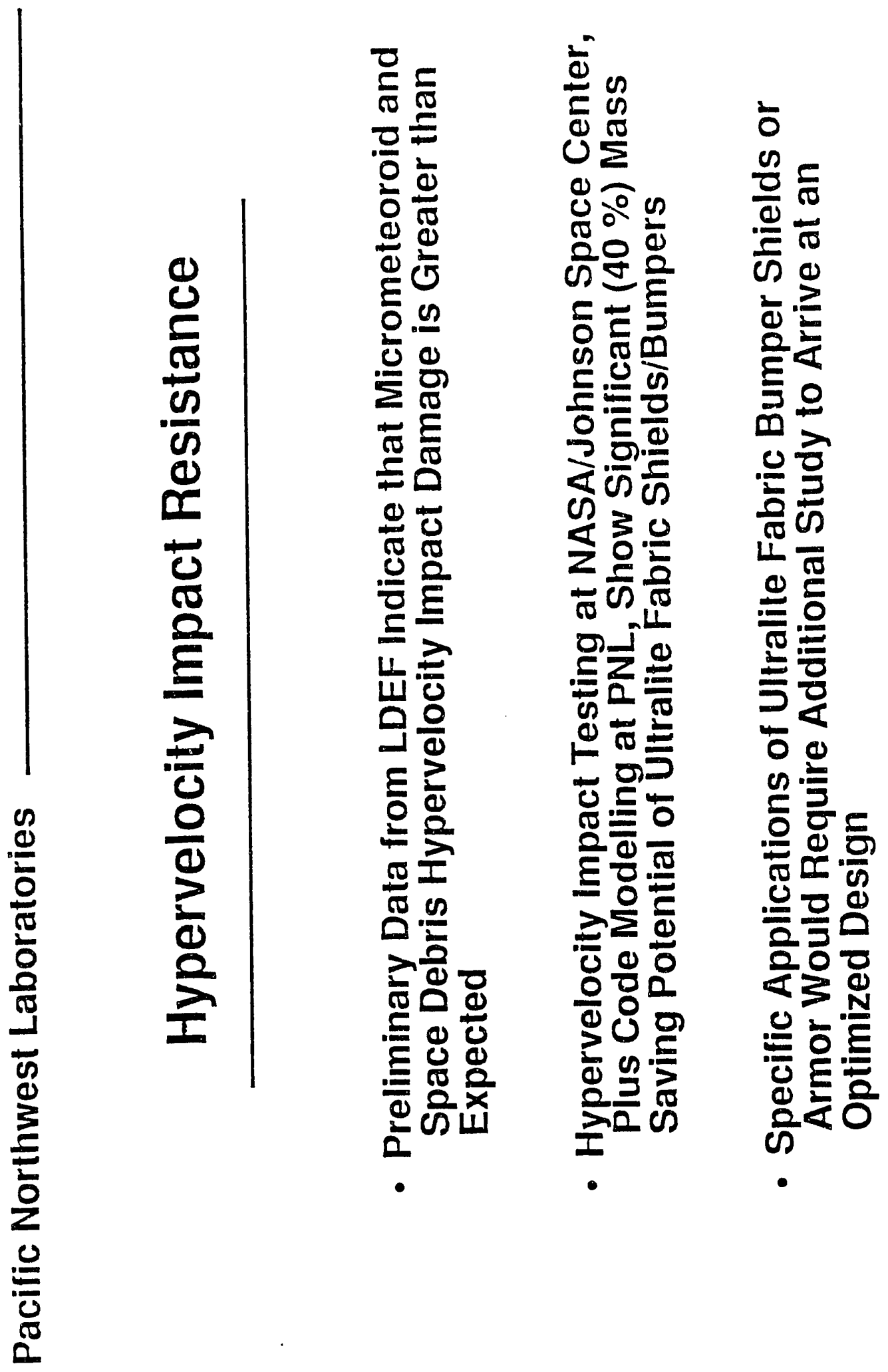



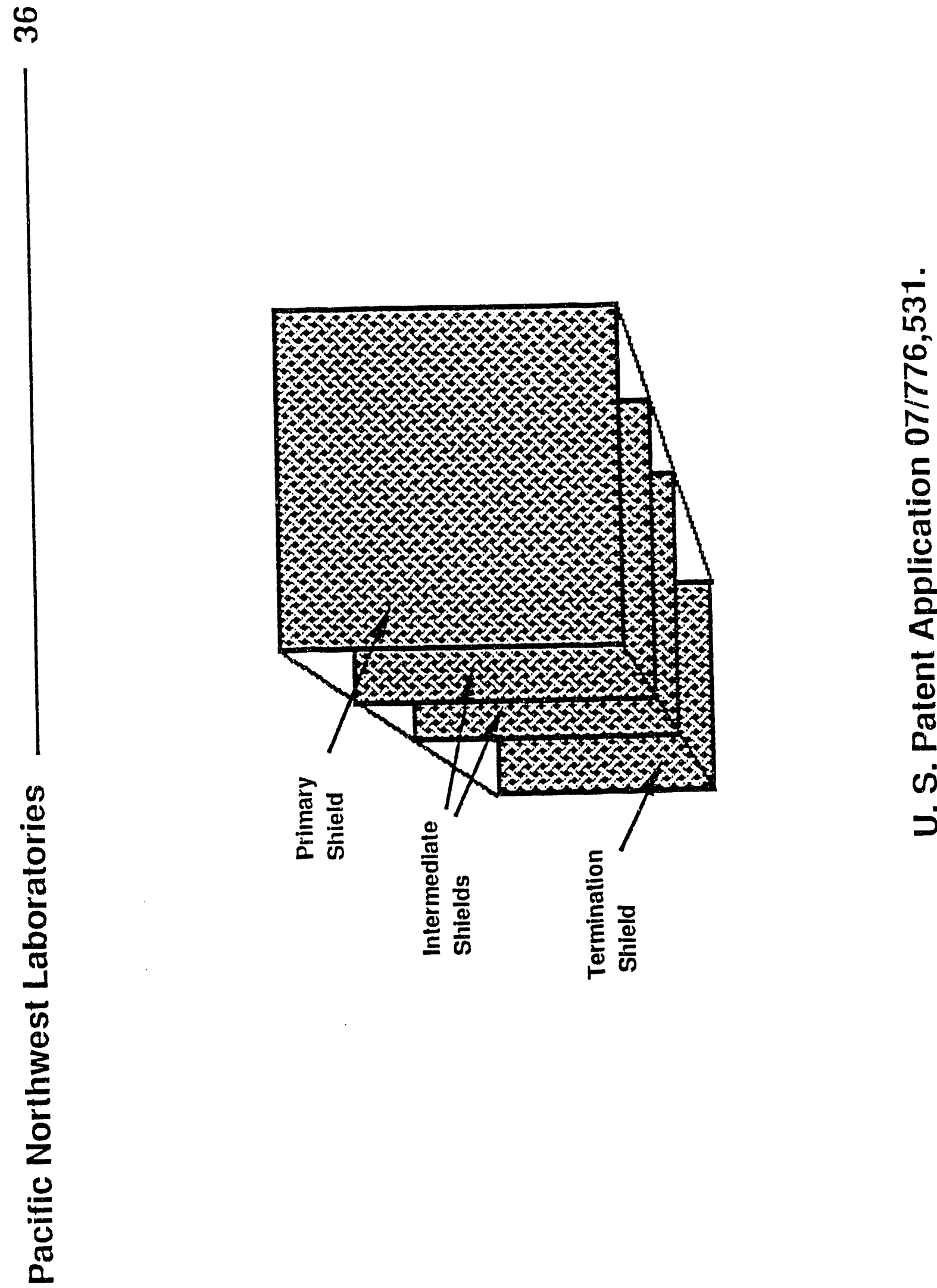

응

$\underline{0}$

을

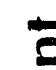

$\frac{E}{\pi}$

2

ci

$\frac{0}{2}$

B. 40 
|

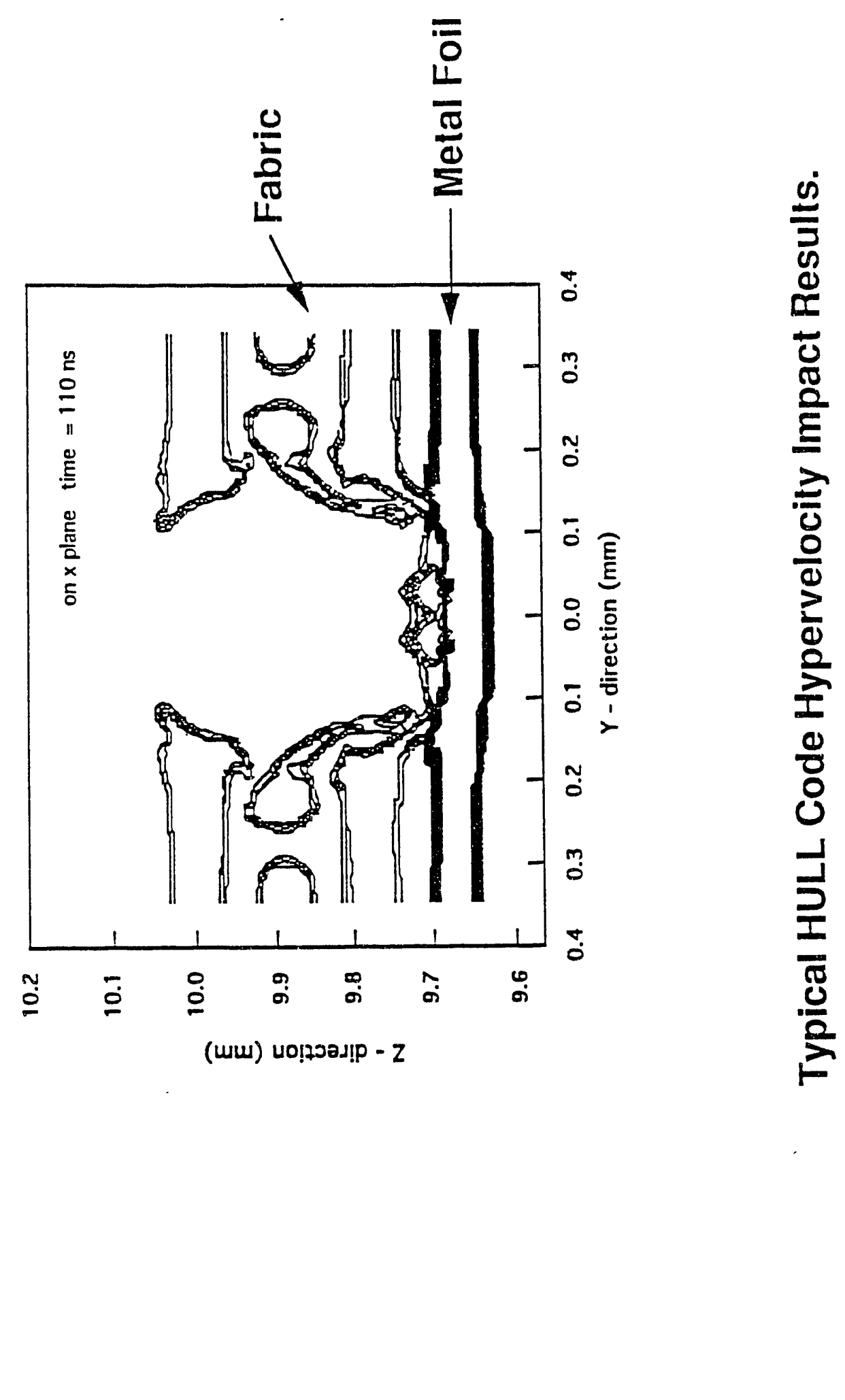




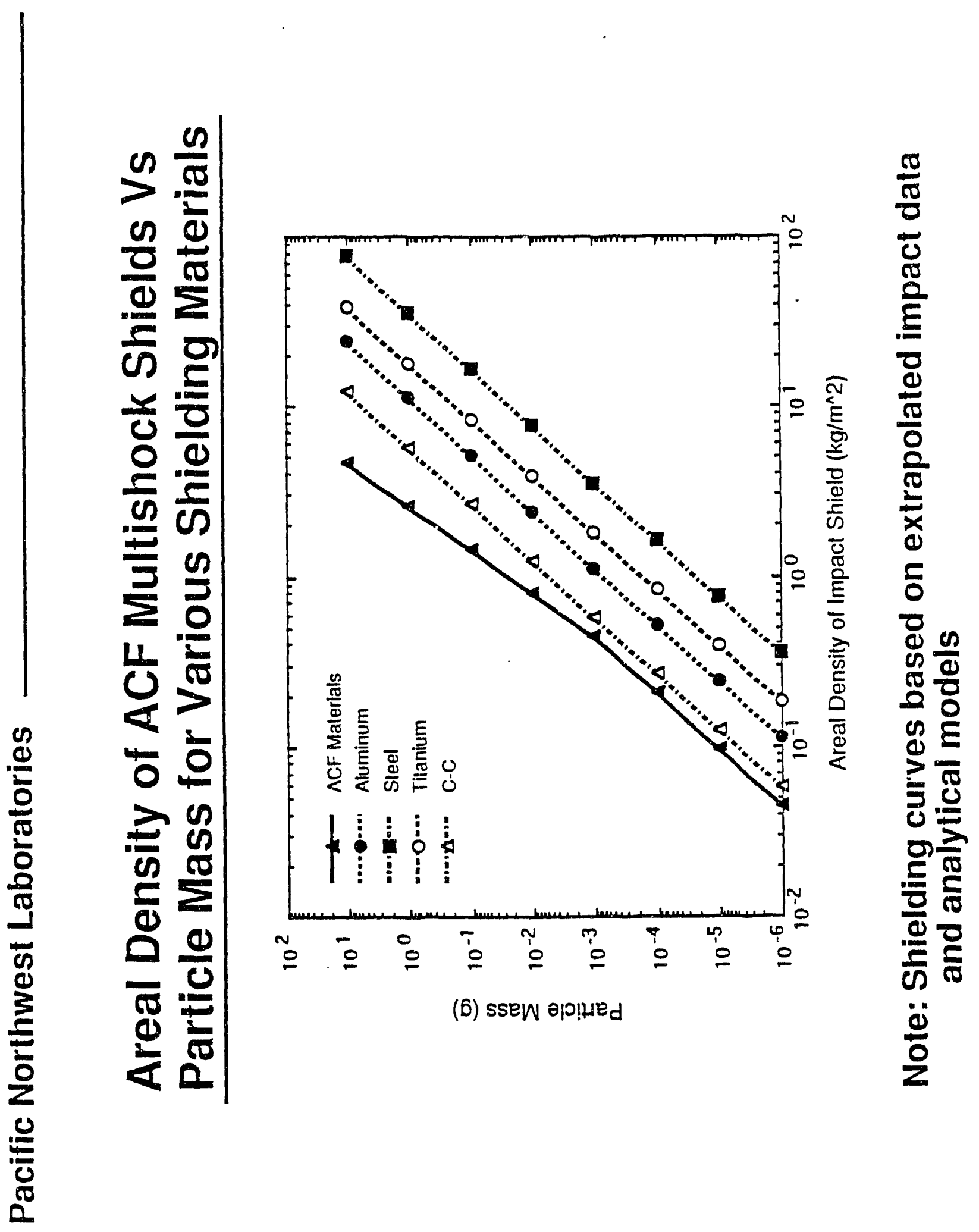


ก

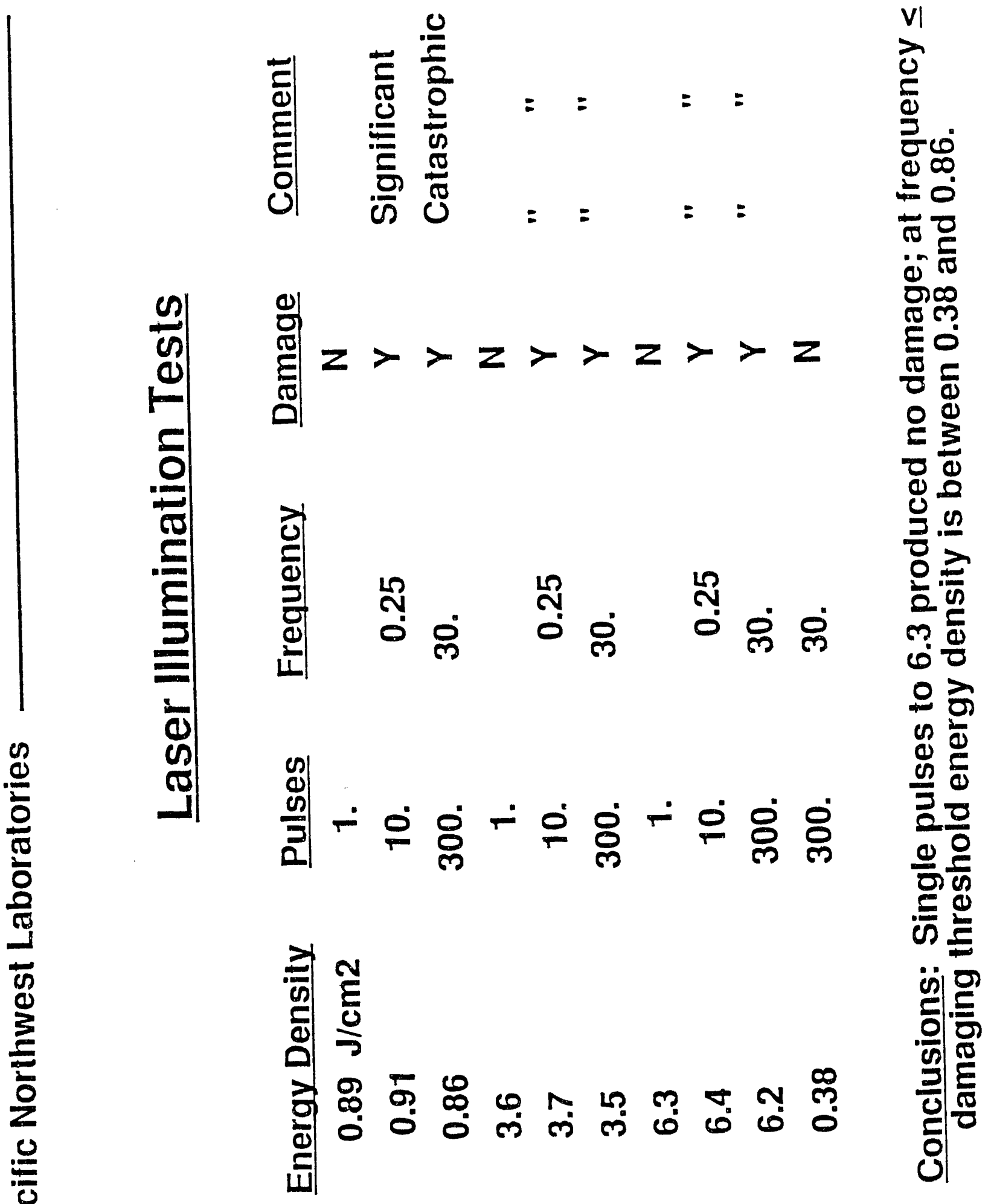


ㅇ

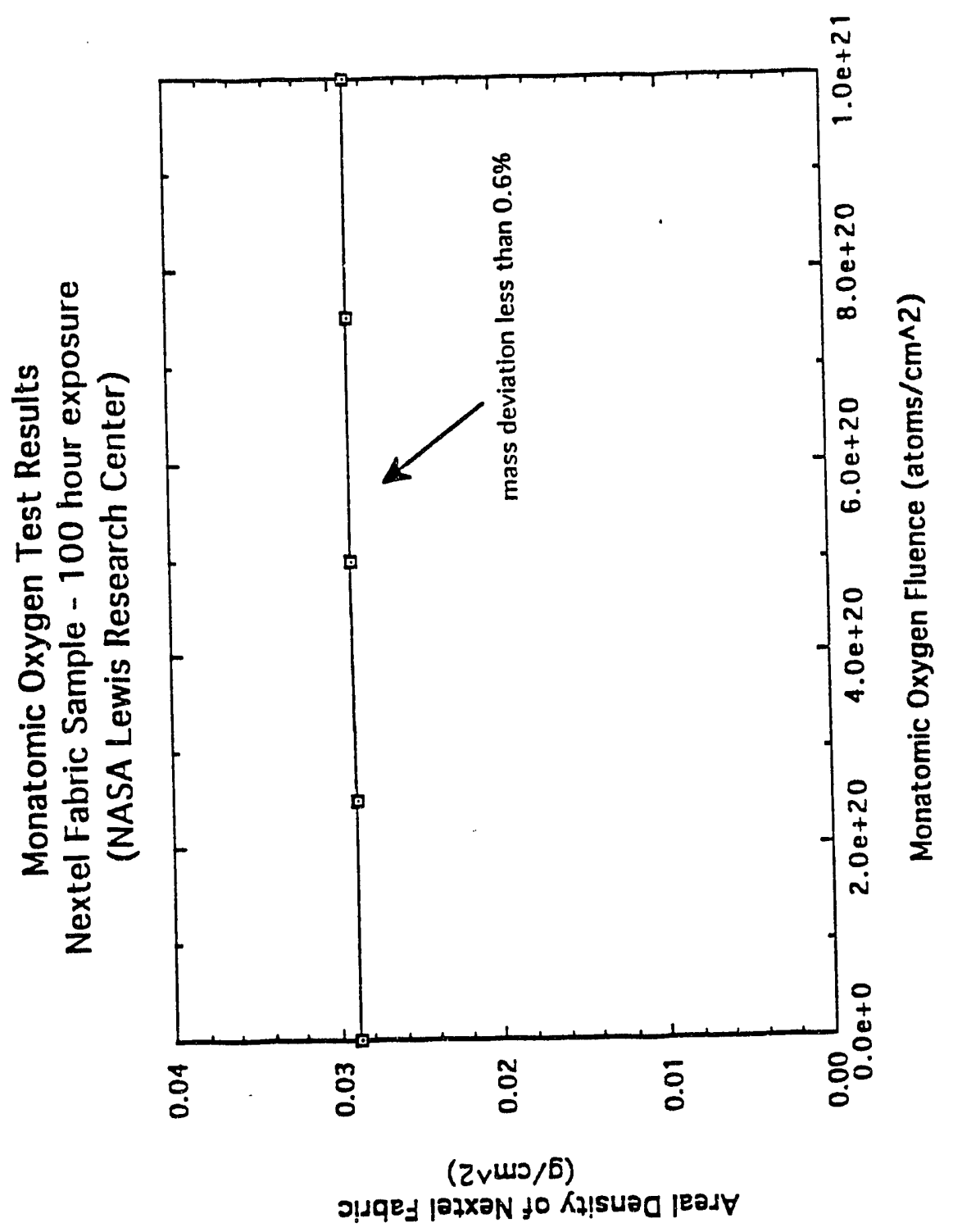

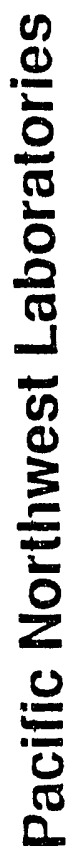




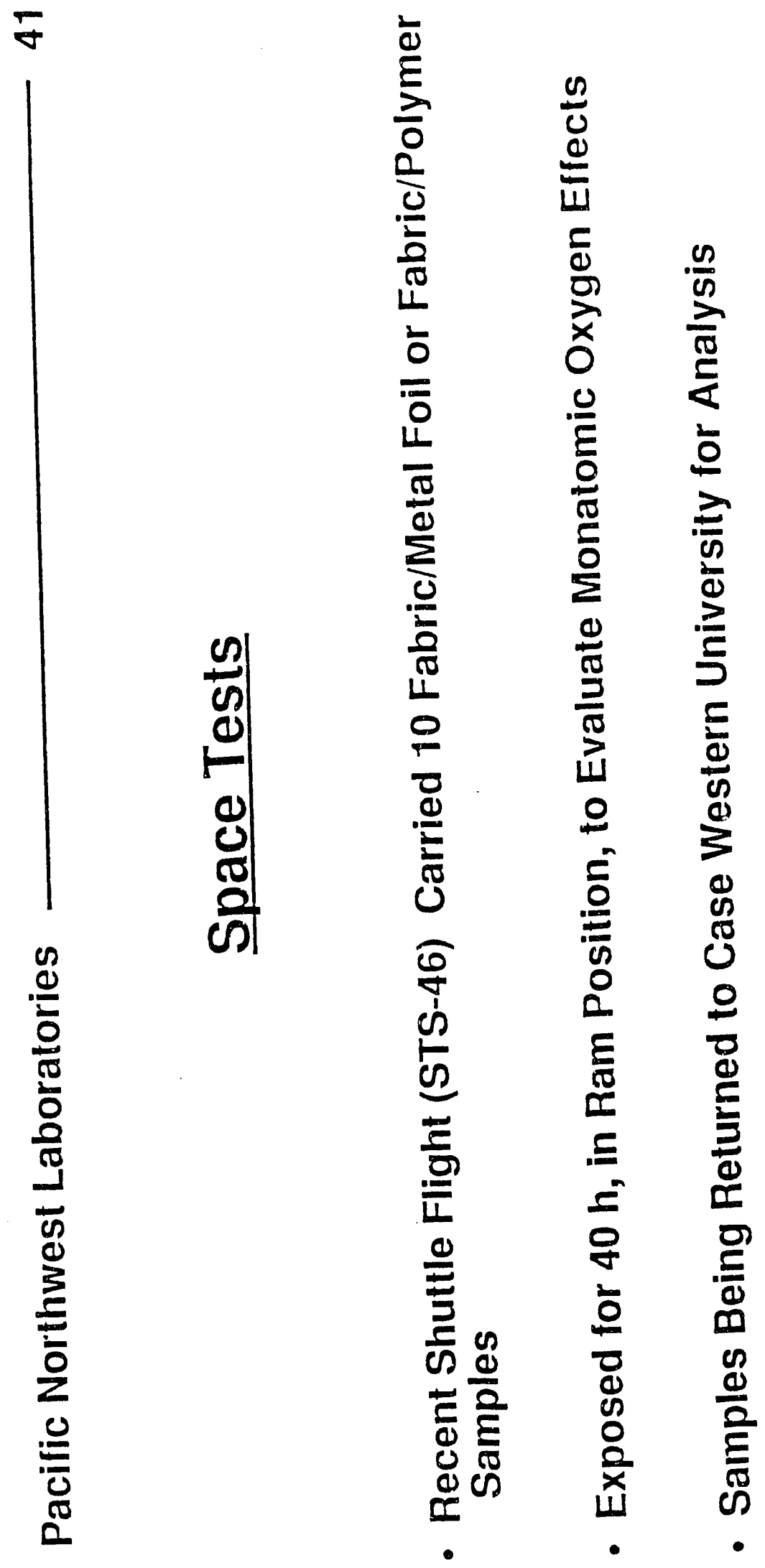

B. 45 
$\checkmark$

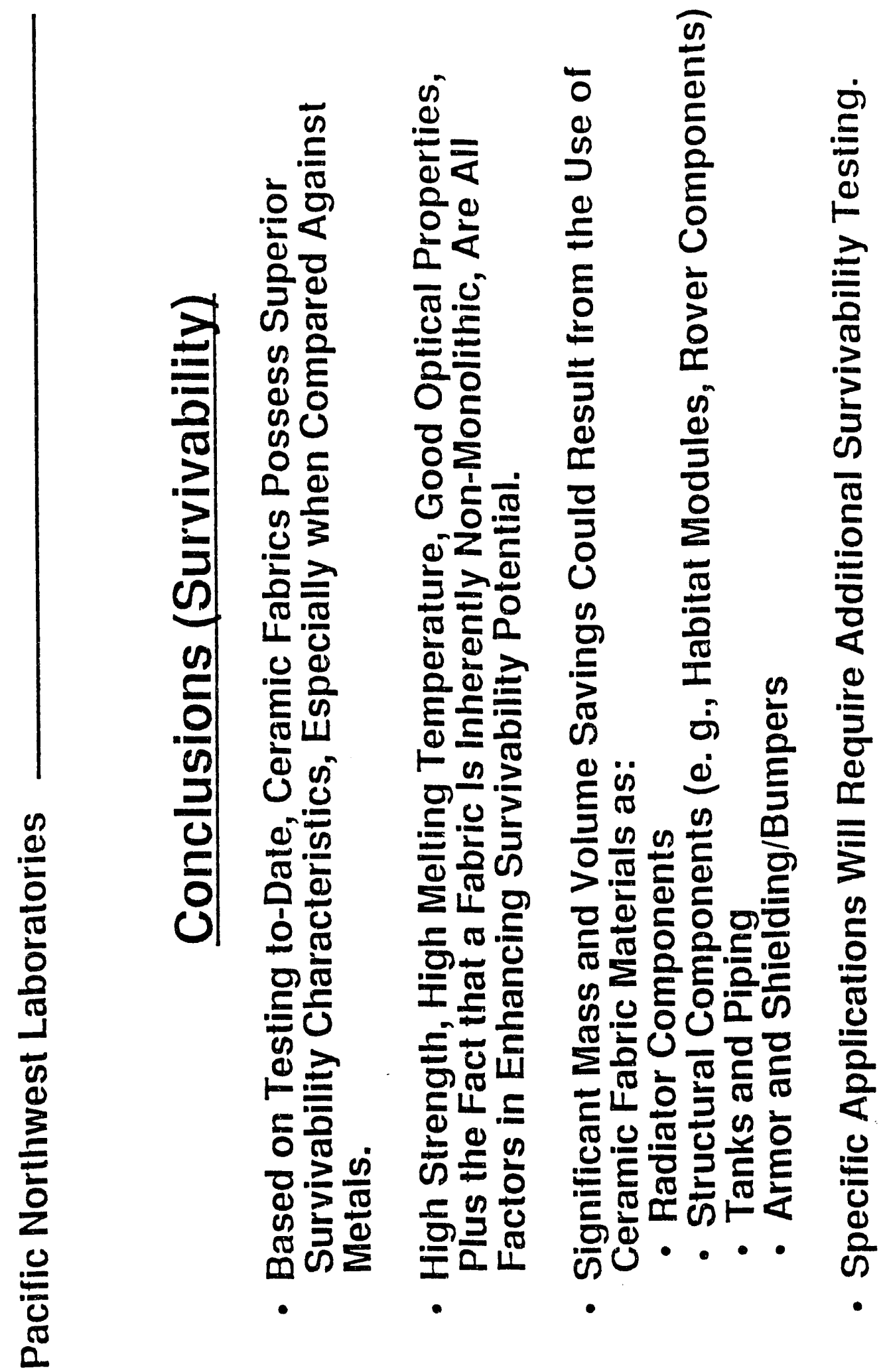




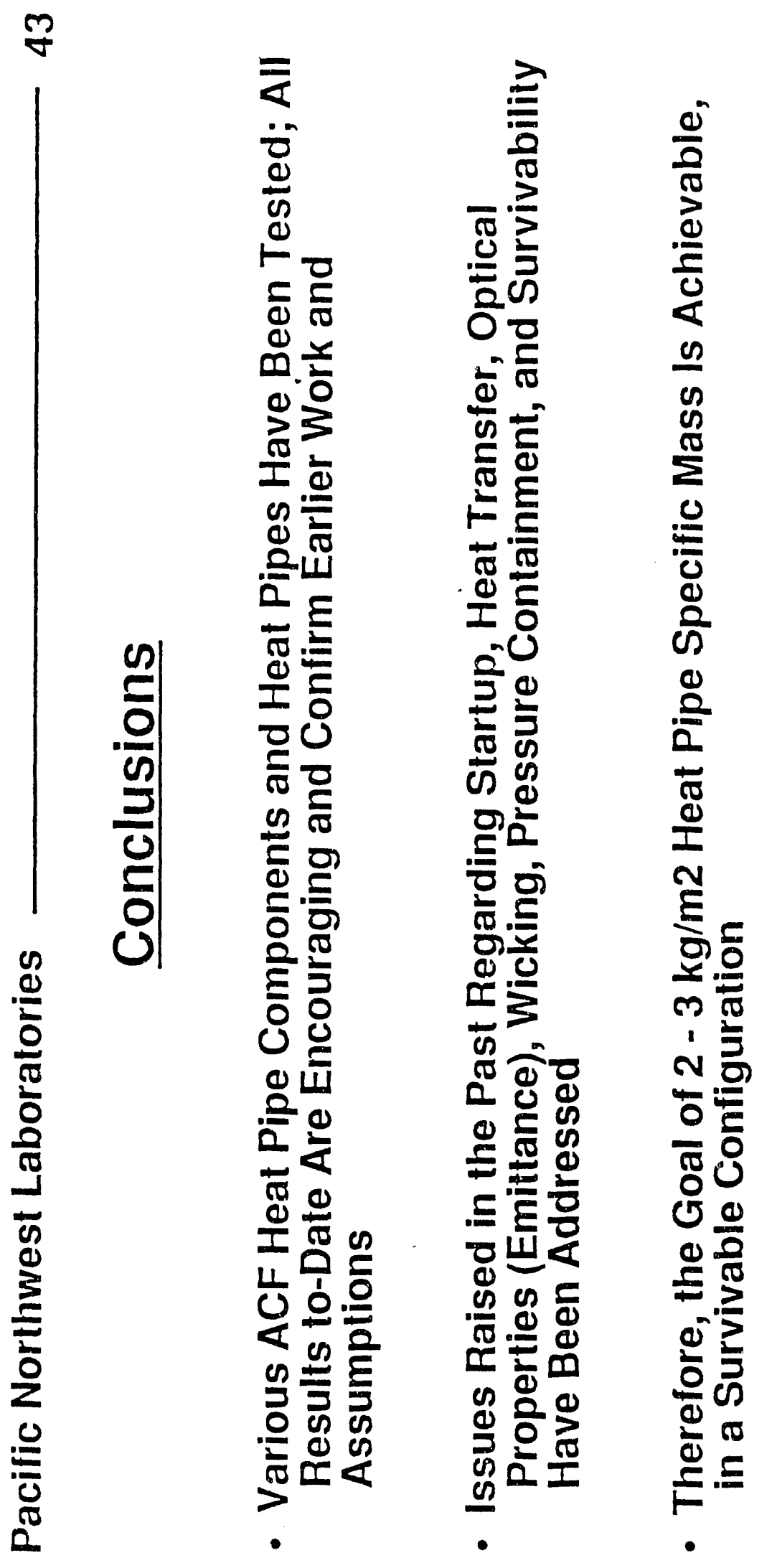




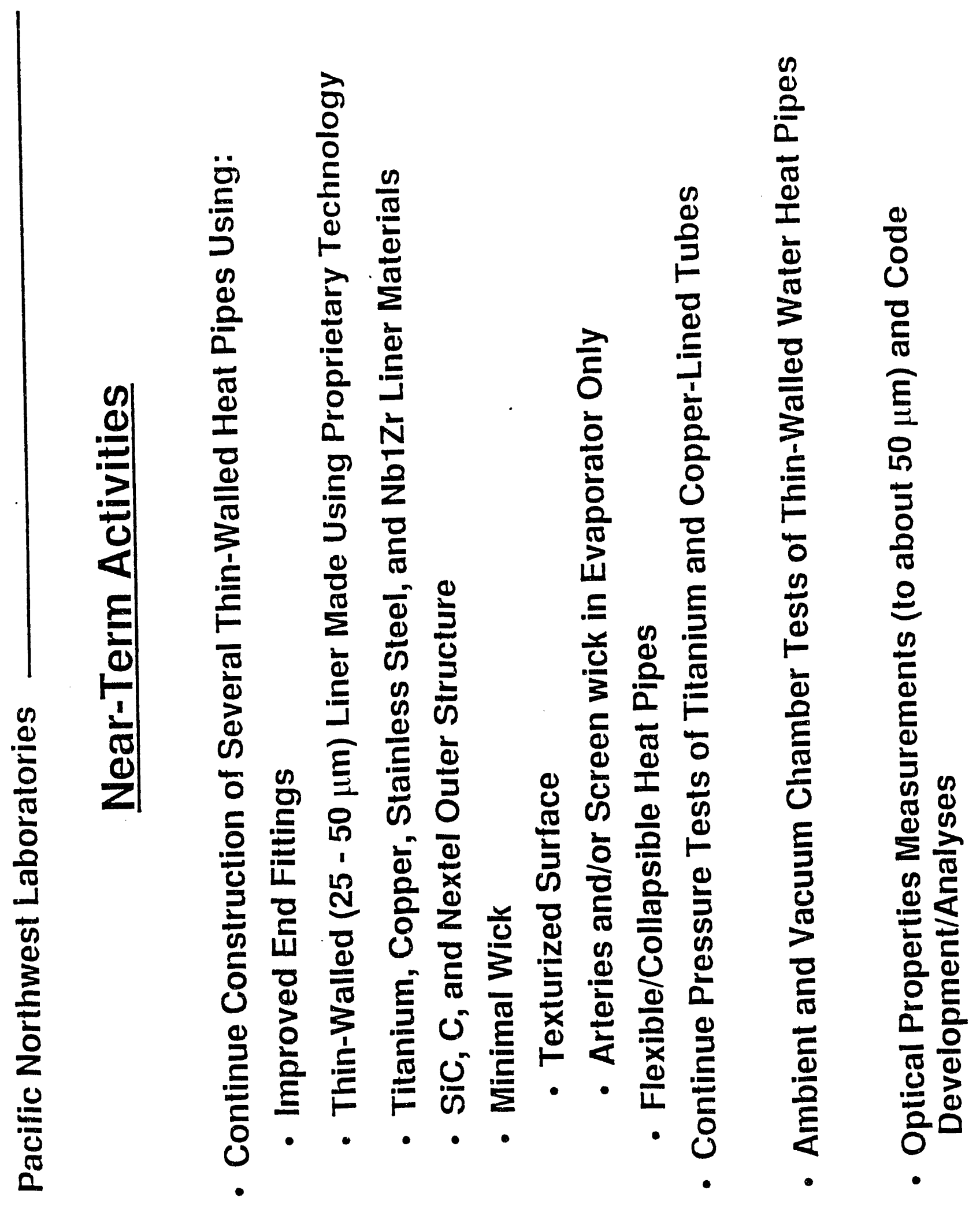


I)

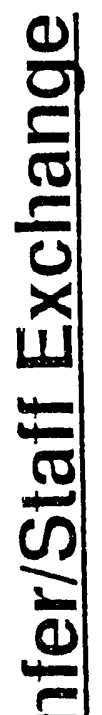

$\begin{array}{ll}\infty & 5 \\ 0 & 2 \\ 0 & 0\end{array}$

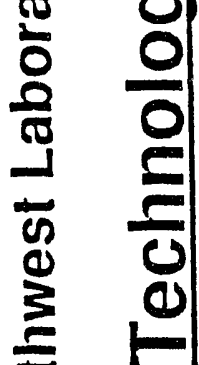

J

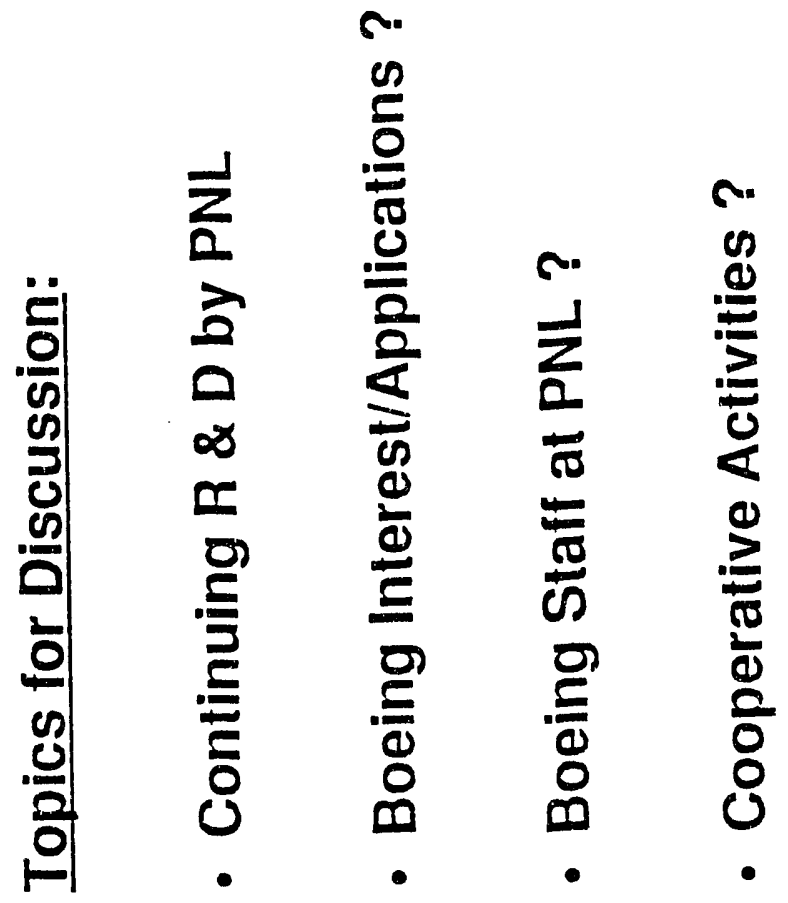

B. 49 


\section{Distribution}

No. of

Copies

OFFSITE

2 DOE/Office of Scientific and Technical Information

M. Abbott

Laboratory Management Division

U. S. Department of Energy

Office of Energy Research

Forrestal Building (ER-42)

1000 Independence Avenue, SW

Washington, DC 20585

T. Vojnovich

Technical Program Manager

ER Laboratory Technology Transfer

Program

U.S. Department of Energy Research

Forrestal Building (ST-311)

1000 Independence Avenue, SW

Washington, DC 20585

A. M. Zerega

Laboratory Management Division

U.S. Department of Energy

Office of Energy Research

Forrestal Building (ER-42)

1000 Independence Avenue, SW

Washington, DC 20585
No. of

Copies

ONSITE

DOE/Richland Field Office

G. McClure, A5-90

19 Pacific Northwest Laboratory

Z. I. Antoniak, K7-15 (10)

M. Clement, K1-17 .

M. D. Erickson, K7-02

B. H. Harrer, K1-12

Publishing Coordination

Technical Report Files (5)

Distr. 1 

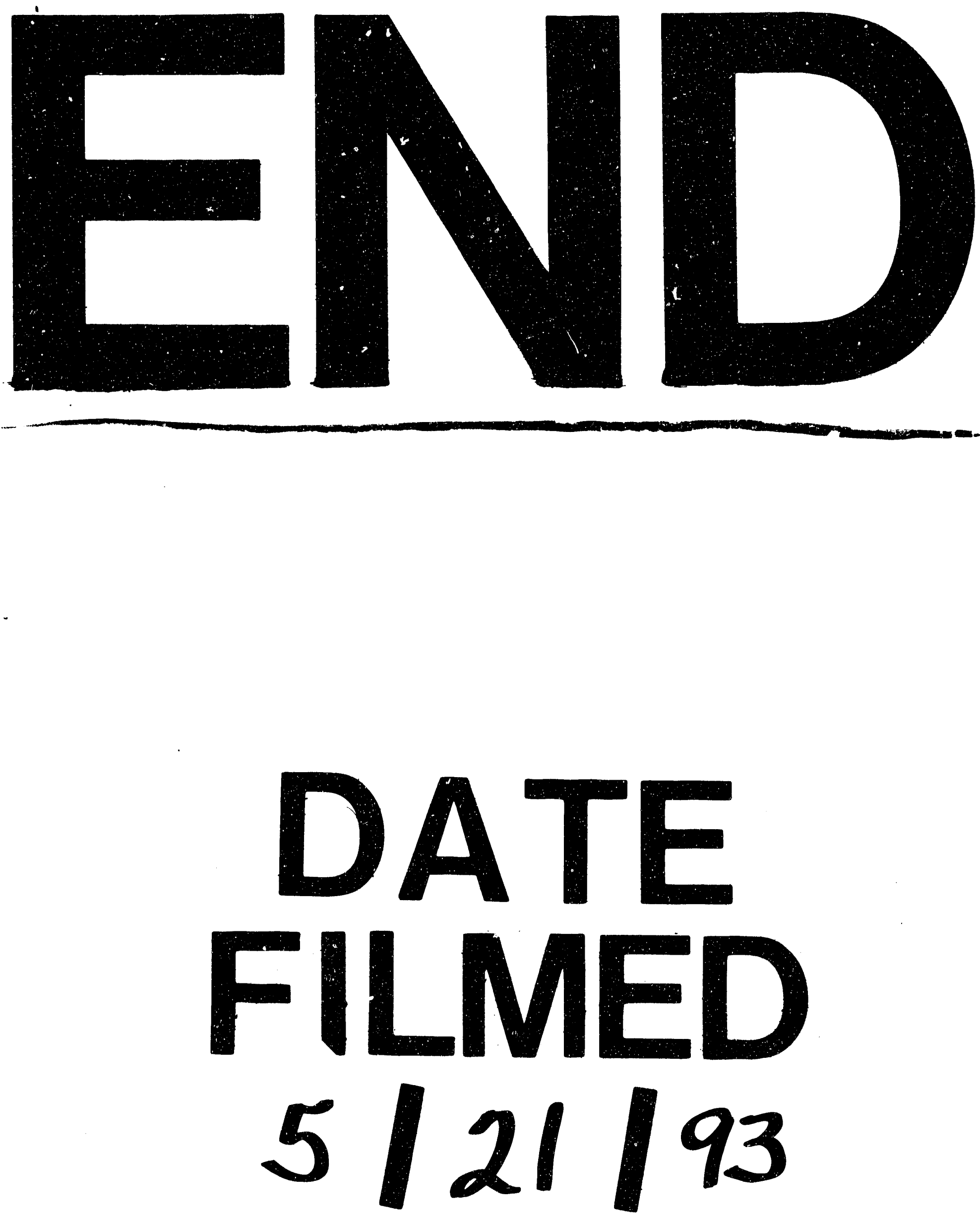


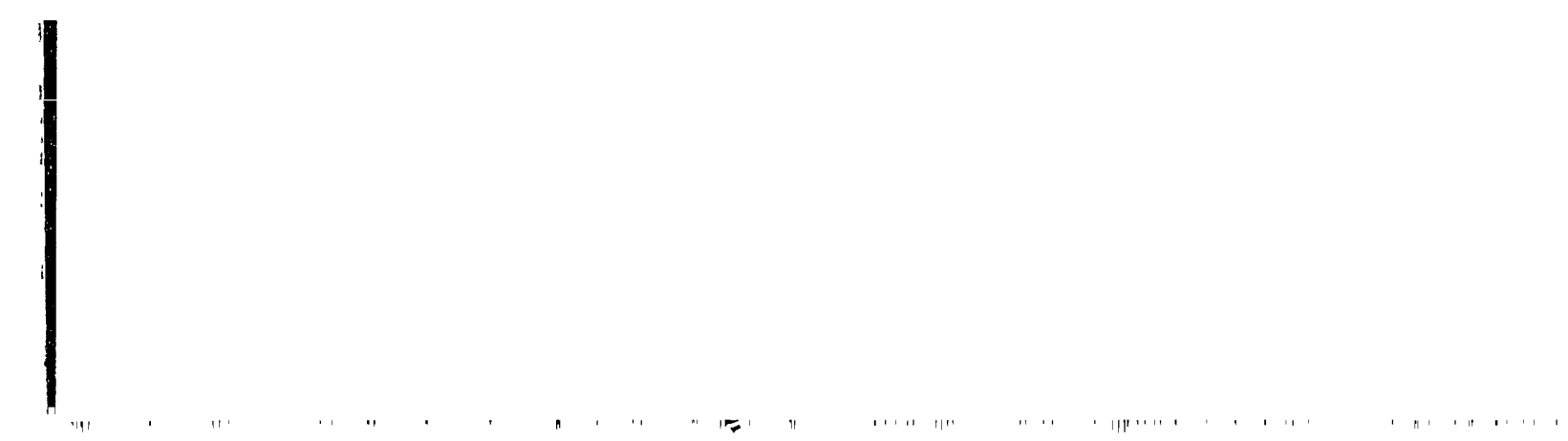

